Running head: EXTRAVERSION AND NETWORK CHURN

\title{
Revisiting Extraversion and Leadership Emergence: \\ A Social Network Churn Perspective
}

\author{
Blaine Landis \\ University College London \\ Jon Jachimowicz \\ Harvard Business School \\ Dan Wang \\ Columbia Business School \\ Robert Krause \\ Free University Berlin \\ In press, Journal of Personality and Social Psychology \\ Author Note
}

We gratefully acknowledge invaluable feedback received from Adam Smith, Joshua Becker, Tom Taiyi Yan, Steve Borgatti, and members of the reading group at University College London. We thank Julian Arango for his tireless assistance collecting data for Study 2. An earlier version of this paper was presented at the $79^{\text {th }}$ annual meeting of the Academy of Management in Boston Massachusetts, August 2019.

Correspondence concerning this article should be addressed to Blaine Landis, University College London, School of Management, One Canada Square, London E14 5AA, United Kingdom. Email: b.landis@ucl.ac.uk 


\title{
Revisiting Extraversion and Leadership Emergence:
}

\section{A Social Network Churn Perspective}

\begin{abstract}
One of the classic relationships in personality psychology is that extraversion is associated with emerging as an informal leader. However, recent findings raise questions about the longevity of extraverted individuals as emergent leaders. Here, we adopt a social network churn perspective to study the number of people entering, remaining in, and leaving the leadership networks of individuals over time. We propose that extraverted individuals endure as emergent leaders in networks over time, but experience significant changes in the people being led, including the loss of people who once considered them a leader but now no longer do. In Study $1(N=545)$, extraverted individuals had a larger number of new and remaining people in their leadership networks, but also lost more people, above and beyond differences in initial leadership network size. In Study $2(N=764)$, we replicated and extended these results in an organizational sample while controlling for alternative explanations such as formal rank, network size, self-monitoring, and narcissism. Extraversion predicted the number of people entering, remaining in, and leaving leadership networks over time. Our findings suggest that while extraverted individuals tend to emerge as leaders, they are also more likely to experience greater network churn - they tend to lead different people over time and leave people in their wake who once perceived them a leader but now no longer do. We discuss the challenges posed by this network churn perspective for extraverted emergent leaders and highlight its importance for our understanding of extraversion and emergent leadership.
\end{abstract}

Keywords: extraversion, social networks, emergent leadership 
Extraversion plays a key role in our understanding of how people navigate social life. A question of perennial interest in the personality and social psychology literature is how extraversion affects our social relationships (Mund et al., 2018). Among the many important social relationships that have been studied, few have received as much attention as the link between extraversion and emergent leadership -i.e., who is perceived as leaderlike (e.g., Judge et al., 2002; Lord et al., 1986). Extraversion is the most consistent personality correlate of emergent leadership among the Big Five traits (Judge et al., 2002). Small group studies show that socially assertive (i.e., extraverted) people tend to speak up often, which signals competence and engenders perceptions of leaderlike qualities among observers (Anderson \& Kilduff, 2009; Ensari et al., 2011; Mullen et al., 1989). Experimental research indicates that individuals told to act extraverted tend to be rated by their peers as emergent leaders, above and beyond their levels of trait extraversion (Spark \& O’Connor, 2020). Collectively, this body of research has received considerable media attention (e.g., Coggan, 2020; Lufkin, 2021; Percy, 2019), shaped teaching practices concerning how to be seen as a leader (e.g., Snook et al., 2012), and been the focus of several popular books (e.g., Cain, 2012; Kahnweiler, 2018).

Several lines of evidence, however, have surfaced that raise questions about the apparent longevity of extraverted individuals as emergent leaders. For example, extraverted individuals tend to lose status over time because they can be disappointing contributors to group tasks (Bendersky \& Shah, 2013). The warmth and assertiveness facets of extraversion may only promote peer liking and advice seeking up to a point, after which these qualities become detrimental to perceptions of emergent leadership (Hu et al., 2019). There is also evidence suggesting that the effects of extraversion wane over time: Peers may value extraversion in the beginning, but then value other qualities in their leaders after a period of socialization (Kalish \& Luria, 2021). Against this backdrop of mixed findings, a critical 
question concerns whether extraversion affects emergent leadership beyond a single time point.

Here, we take a novel approach to elucidate what happens to extraverted individuals as emergent leaders with the passage of time. We offer a network churn perspective (e.g., Sasovova et al., 2010) whereby extraversion affects changes in the network of people who consider someone a leader. This perspective rests on the notion that in social environments where people have opportunities to interact with others, leadership relations are susceptible to change. Extraverted individuals' tendencies to exhibit assertive, sociable patterns are likely to increase the likelihood that they attract new ties from individuals who previously did not consider them a leader but now do, as well as keep some ties from individuals who considered them a leader before. But as we suggest below, extraverted individuals' tendencies may also become disruptive, which, over time, may increase the likelihood that they lose some of the individuals who once considered them a leader. If supported, this perspective suggests a network pattern where extraverted individuals experience changes in network composition as they lose ties, keep ties, and attract new ties. Thus, this perspective highlights that extraverted individuals may endure as emergent leaders but do so among a changing set of followers — which could create challenges for their ability to lead.

We provide empirical evidence for our network churn perspective across two social network studies (Study $1 N=545$, Study $2 N=764$ ), where we study how extraversion relates to changes in the number of individuals entering, remaining in, and leaving a person's social network over time. This network approach captures the number of people who perceive a focal individual as leaderlike, allowing us to count the number of people lost, maintained, and added to the network over time. As such, this paper helps clarify a classic line of inquiry in the personality psychology literature, showing that the notion of extraverted individuals as emergent leaders is incomplete. Rather, these findings indicate that extraversion is linked to 
emergent leadership, but perhaps not in the way that classic research suggests - extraverted individuals, relative to their introverted counterparts, do indeed have larger networks of people who perceive them as a leader over time, but they also leave in their wake people who once considered them a leader but now no longer do.

\section{Extraversion and Social Networks}

Social network approaches capture relationships between individuals where a focal person (ego) is claimed by others (alters) as a leader (Carter et al., 2015; Wasserman \& Faust, 1994). Emergent leaders are those who have a large number of people in the network who claim them as a leader. Our focus is on leadership emergence, which concerns "being perceived as leaderlike" (Hogan et al., 1994, p. 496) and attaining recognition in settings above and beyond formal leadership roles (Mann, 1959). This approach captures informal patterns of social interaction regarding who looks to whom for leadership (Brass \& Krackhardt, 1999). These leadership relations reflect informal social interaction patterns that may or may not match formal roles in a social setting (Krackhardt \& Hanson, 1993). Studying these emergent and informal leadership perceptions is critical because of the limits of formal authority required to influence others (Hogan et al., 1994).

We study changes at each individual's network level (i.e., the number of lost, old, and new ties) because our perspective concerns the amount of change in the person's ego network, rather than the likelihood that a single relationship will change (i.e., the tie level). Social networks comprised of leadership ties can feature changes in the number of people who did not consider the focal person a leader at a previous time point but now do (new leadership ties), the number of people who considered the focal person a leader at a previous time point and still do (persistent leadership ties), and the number of people who considered the focal person a leader at a previous time point but now no longer do (lost leadership ties). Social network change therefore captures variability in who considers the person a leader, as 
reflected in these three outcome measures. This network approach answers calls to "pay more attention to social network perspectives" (Denis et al., 2012, p. 211). As noted in one recent review, scholars noted that "there is likely no more pressing need than to incorporate temporal processes to better understand the complexity inherent in emergent leadership" (Hanna et al., 2021, p. 95). These social network changes are depicted in Figure 1.

Insert Figure 1 about here

Note that we draw a distinction here between social network size and social network change. The link between extraversion and social network size has been investigated in several prior studies. For example, extraversion is related to the number of friends one has over time (i.e., network size; Feiler \& Kleinbaum, 2015; Selden \& Goodie, 2018; van Zalk et al., 2020), in line with other research showing that extraverted individuals have larger networks (Asendorpf \& Wilpers, 1998; Pollet et al., 2011; but see Fang et al., 2015). However, there is evidence suggesting that the effect of extraversion on emergent leadership size may wane over time (Kalish \& Luria, 2021), and that emergent leadership perceptions may be diminished by a "too-much-of-a-good-thing" effect from the warmth and assertiveness facets of extraversion (Hu et al., 2019). We recognize that individuals have leadership networks of varying sizes and that some of this variability is associated with extraversion. This paper, however, examines the amount of social network change that occurs in each person's network over time. Specifically, we investigate how (a) in social environments where individuals are allowed to choose who they perceive as a leader, leadership relations are susceptible to change, and (b) controlling for the size of leadership networks, extraversion is related to these changes (i.e., the number of people entering, remaining in, and leaving a focal person's leadership network over time). Collectively, we 
refer to these greater changes in networks among extraverted individuals as network churn (Sasovova et al., 2010).

\section{New People Entering the Leadership Network}

Extraversion is defined as the extent to which someone is outgoing, active, assertive, enthusiastic, and sociable with others (McCrae \& John, 1992). Indeed, extraverted individuals are often defined in part by their tendency to engage in sociable and assertive behaviors: They are less apprehensive about communicating with others (Opt \& Loffredo, 2000), have a greater desire to speak in front of larger audiences (Feingold, 1983), and are less likely to speak quietly (Scherer, 1978). Assertiveness can lead to enhanced social influence, as extraverted individuals typically receive more social attention at work (Ashton et al., 2002) and are more likely to be heard (Crant et al., 2011; LePine \& Van Dyne, 2001).

These sociable, assertive behaviors which extraverted individuals more commonly engage in are direct verbal acts that help promote the perception of extraverted individuals as informal leaders, which followers grant to leaders because they conform to followers' stereotypes of what a leader is and how one should behave (Hogan \& Kaiser, 2005). Extraverted individuals spend more time talking (Ensari et al., 2011; Mehl et al., 2006, but see MacLaren et al., 2020) and, as small group research shows, the length of communication signals dominance and predicts leadership emergence (Anderson \& Kilduff, 2009; Mullen et al., 1989). In addition, extraverted individuals may be perceived as leaderlike by engaging in direct nonverbal behaviors that others interpret as conforming to what it means to be a leader (e.g., looking the part or sitting at the head of a table; DeRue \& Ashford, 2010, p. 632).

In addition to these direct verbal acts, extraverted individuals may attract more followers in leadership networks than their introverted counterparts due to indirect nonverbal tendencies. For example, extraverted individuals are less likely to be alone in daily life (Mehl et al., 2006), which suggests that extraversion relates to opting into more social situations at 
work. Extraverted individuals may also leave "behavioral residue" in the workplace (Gosling et al., 2002) that signals informal leadership, such as achievements in leadership domains (e.g., an executive education certificate for a leadership course). Taken together, this logic suggests that extraversion is likely to be positively related to the number of new people entering a person's leadership network over time.

\section{People Remaining in the Leadership Network}

A critical part of capturing networks over time is understanding who retains ties from an earlier time point. Retaining a larger number of people in the leadership network can be a source of advantage because longstanding ties may support stronger relationships between leaders and followers (e.g., see Bolger \& Eckenrode, 1991; Bolger et al., 1996). In contrast, losing a larger number of people in the leadership network could be harmful because these losses could lead to reputational costs (e.g., when followers no longer perceive individuals as leaders and gossip with others about why not; see Feinberg et al., 2012).

Accounting for any differences in the initial size of an individual's leadership network, we suggest that extraverted individuals may be likely to retain more people in their networks over time. Extraverted individuals experience more positive moods (Watson \& Clark, 1997), engender positive affect in others (Eaton \& Funder, 2003), and have lower levels of emotion suppression (Vater \& Schröder-Abé, 2015). Indeed, the link between behaving in an extraverted manner and experiencing positive affect has consistently emerged from personality science (Fleeson et al., 2002; Kuijpers et al., 2021; McNiel \& Fleeson, 2006; McNiel et al., 2010; Smillie et al., 2012; Smillie et al., 2015; Watson \& Clark, 1997; Zelenski et al., 2013). Moreover, in research probing the mediators of the relationship between enacting extraversion and positive affect, evidence suggests that positive social experiences (e.g., perceived impact on social world, perceived contribution to a discussion) are likely mechanisms (Smillie, 2013). Furthermore, the enthusiasm and energy of 
extraversion can be contagious (Vinchur et al., 1998). Extraverted individuals tend to use more positive emotion and social process words (Chen et al., 2020). This increased enthusiasm and positive affect in social dynamics may help explain why extraverted individuals report greater satisfaction with their friends (Wilson et al., 2015). Positive emotional energy is likely to bode well for an extraverted person's ability to maintain people in the network, suggesting a positive relationship between extraversion and the number of people remaining in the leadership network over time.

\section{People Leaving the Leadership Network}

While extraverted individuals may be more likely to retain some people in their leadership network, we propose that they may also be more likely to lose more people in their leadership network over time. First, the tendency for extraverted individuals to be less inhibited about speaking (Opt \& Loffredo, 2000), to speak more frequently (Mehl et al., 2006), and to be less likely to speak quietly (Scherer, 1978) can bode well for followers perceiving extraverted individuals as leaders — but these same tendencies may elevate the risk that extraverted individuals dominate conversations by speaking too much. For instance, extraversion is related to being blirtatious, i.e., speaking often and rapidly in unstructured interactions (Swann \& Rentfrow, 2001). The higher the extraversion, the more likely people may be to dominate conversations by speaking too much, thereby eroding the follower's positive impressions of the extraverted individual as an informal leader because they feel left out of conversations. Similarly, extraversion may lead to a loss of people over time because extraverted individuals may be less likely to listen. Extraversion may increase the risk that individuals "quickly bounce from one conversation or idea to another" (Judge et al., 2009, p. 868), irritating people because they feel their comments or ideas are being ignored.

Second, extraversion may be associated with being unreceptive to others' ideas and suggestions (e.g., Grant et al., 2011; Judge et al., 2009). People look for and respond to 
leaders who make them feel that their ideas and suggestions are valued (Grant \& Gino, 2010; Grant et al., 2009). Because extraverted individuals want to be the center of attention (Judge et al., 2009), incorporating others' ideas and suggestions may steal the spotlight away from them and therefore make them less likely to focus on others' input. In turn, extraverted individuals' tendency to be unreceptive to others' ideas and suggestions may signal that they "have self-interested objectives," which enhances the likelihood that people will perceive extraverted behaviors as self-aggrandizing rather than helpful (Bendersky \& Shah, 2013, p. 389).

Third, extraverted individuals may be perceived as overly assertive. Although a certain amount of assertiveness is necessary for being perceived as a leader (Ames et al., 2017; Hogan \& Kaiser, 2005; Hu et al., 2019), at the high end of assertiveness, leaders tend to be evaluated as ineffective because they prioritize instrumental outcomes at the expense of relational outcomes, which hurts leadership evaluations (Ames \& Flynn, 2007). Thus, extraverted individuals may be prone to be seen as trying to get their own way (i.e., assert themselves) to the detriment of others. In empirical research investigating the effects of both variables on leadership outcomes, extraversion and assertiveness were positively related to each other, but only assertiveness had a curvilinear effect on leadership evaluations (Ames \& Flynn, 2007). This pattern of relationships implies that extraverted individuals could be seen as being more prone to assertive behaviors, which (past a certain point) leads to negative leadership outcomes.

Finally, extraverted individuals tend to be motivated by a desire for status (Anderson et al., 2001; Barrick et al., 2002). Indeed, extraverted individuals may be inclined to "behave in bold, aggressive, and grandiose ways" (Judge et al., 2009, p. 868). This desire for status may manifest in boasting about past achievements or exaggerating what one has done, resulting in negative reactions from others. Prior research highlights that attempting to 
enhance one's status can lead to social costs, including being liked less by others and being paid less for work (Anderson et al., 2008a). Given extraverted individuals' desire for status, they may exaggerate achievements or appear boastful, which in turn may lead to a larger number of people leaving their leadership networks over time. Thus, we predict that there is a positive relationship between extraversion and the number of people leaving leadership networks over time.

\section{Overview of Studies}

In two studies, we tested how extraversion relates to network churn, i.e., changes in the number of people entering, remaining in, and leaving an individual's leadership network over time. In Study $1(N=545)$, we investigated how extraversion predicts changes in the emergent leadership networks among a new cohort of potential leaders (MBA students) across two time points. In Study $2(N=764)$, we replicated these effects in a Latin American professional setting where we established that these effects occur above and beyond formal organizational leadership roles and alternative explanations regarding other personality traits (e.g., narcissism, self-monitoring).

\section{Study 1: Method}

\section{Participants}

We examined the emergence of leaders across two time points in a cohort of potential leaders (MBA students) at a private university in the Northeastern United States. This setting provided an opportunity to examine leadership perceptions in a situation largely free from the constraints of organizational structures, providing a direct test of leadership emergence. Samples drawn from formal organizations may provide wider generalizability but also present challenges to making clean inferences about the influence of personality due to selection problems (Mouw, 2006). That is, selection problems arise in organizational settings because peer groups are endogenous, heightening the possibility that the personality effects 
of extraversion are due to unmeasured variables. In line with prior research that has exploited natural experiments where people are randomly assigned to social settings (for example, see Hasan \& Bagde, 2015; Kleinbaum, 2018), we investigate network change in a setting where this occurs: MBA students are quasi-randomly assigned to one of eight sections, each consisting of approximately 70 students. Each section is created by stratified random sampling to approximate a representative cross-section of the entire cohort of students in terms of gender, race, age, country of origin, and industry background. Because each individual in our sample was asked to rate the emergence of leaders in a quasi-random selection of cohort members (i.e., individuals interact with and choose from peers within their respective randomly assigned sections, all of whom should be approximately equal with respect to demographics and industry background), we were able to minimize identification issues associated with the initial selection problem.

The MBA program offered ample opportunities for social interaction and informal leadership behavior. Prior to the start of the academic year, students within each section experience a two-week orientation program in which they take part in team-building activities, social events, and other training programs. Toward the end of the second week (after spending approximately 75 hours interacting with each other), students in each section hold elections for formal leadership positions within each section, such as chair or alumni representative. The purpose of these elected leadership roles is to formalize a collective decision-making structure for a variety of common goals and tasks for which each section is responsible. For example, each section is required to coordinate a section-wide community volunteer effort each semester. This task entails selecting a volunteer project, appointing coordinators, and preparing training sessions. Furthermore, each section is also allocated a budget they may use to hold events, compensate guest speakers, or donate to a charity of their choice. Critically, each section is also expected to develop ties with alumni of the school by 
coordinating meetings, events, and mentorship sessions that are meant to benefit each student in the section. Therefore, section leaders must not only develop knowledge about their respective sections' needs and ambitions, but they must also create opportunities to interact with alumni in a timely and productive way. Finally, within the school, sections frequently compete with one another in a number of school-wide events, ranging from more casual contests such as trivia nights to more formal and complex tasks such as fundraising. These between-section competitions often motivate section leaders and students to work together, as success in these contests is impossible without collective mobilization. Students are made aware of how important it is to have leaders in their sections who are able to shepherd them toward these goals. Together, these experiences make the MBA setting an appropriate one for the study of informal leadership emergence. Note that these data were collected before the onset of the COVID-19 pandemic, i.e., all interactions between students were in-person.

In the middle of the first week — which we denote as Time 1 - students were asked to fill out surveys about their beliefs, values, personalities, and other background-related topics. On these surveys, students also nominated up to 10 other students in their sections who they regarded as leaders. Approximately four months later-which we call Time 2 - we emailed a second survey invitation involving the same question about leadership emergence. We received matched responses on both surveys from 545 individuals (out of a possible 556) for a response rate of $98 \%$. The average age of individuals in our sample was $27.98(S D=2.48)$, with women comprising $39.46 \%(n=221)$ of the sample. Please note that due to the sensitive nature of these data, they cannot be made publicly available. Syntax for our models below can be found here: https://osf.io/34kzs/?view_only=ca31e773c7f042a7992eb5ef8db45af8.

\section{Data and Measures}

Leadership networks. In keeping with prior research on leader emergence (Judge et al., 2002; Kalish \& Luria, 2021), our focus here was on whom each person considered to be a 
leader. At Time 1 and Time 2, we asked individuals "Whom do you view as leaders in your section?" Individuals could select up to 10 classmates whom they perceived as leaders. In the survey, each individual saw a list of people in their section, alphabetized by name. To minimize the possibility that people would struggle to identify (and consider) each person on the list, we included a recent professional photo next to their name. Individuals responded by checking the box next to a person's name if they considered this person a leader.

Following prior research (Sasovova et al., 2010), for individual $i$, we coded a leadership tie between persons $i$ and $j$ only if person $j$ claimed person $i$ as a leader. This approach relies on the reports of multiple other people to estimate the extent to which the focal person (ego) is perceived to be a leader and removes concern with self-report biases. It also preserves the asymmetry inherent in the data by not requiring a tie to exist if both people claim it to exist.

Dependent variables: Leadership network churn. Building on a longstanding line of social network research, emergent leaders are those with a larger number of incoming ties: "Prominent leaders are the objects of extensive relations from followers, while the latter are the objects of few relations" (Knoke \& Burt, 1983, p. 199). Count variables have been used frequently in organizational network research where prominence and asymmetric ties are of interest (e.g., Burkhardt \& Brass, 1990; Freeman, 1979; Kilduff \& Krackhardt, 1994). Using the informal leadership network data collected at two time points, we defined three variables capturing the change in the number of leadership perceptions across time.

Specifically, we followed Sasovova et al. (2010) and created three count variables: the number of people who entered the leadership network over time (people added), the number of people who remained in the leadership network over time (people maintained), and the number of people who left the leadership network over time (people lost). People added refers to the number of incoming ties that a person has at Time 2 that were absent at Time 1. 
People maintained refers to the number of incoming ties that a person has at Time 2 that were also present at Time 1. People lost refers to the number of incoming ties a person had at Time 1 that were absent at Time 2. Importantly, our units of analysis are the counts of incoming ties, that is, people added, maintained, and lost in the network across time points. These counts reflect the number of changes in incoming ties - the extent to which other people claim the focal person (ego) as a leader.

Predictor variable: Extraversion. We measured extraversion with the items “extraverted, enthusiastic," and "reserved, quiet" (reverse-scored), taken from the established 10-item personality inventory (TIPI; Gosling et al., 2003). Participants rated the extent to which these adjective pairs applied to them on a seven-point Likert scale, and the SpearmanBrown reliability statistic for assessing the reliability of a two-item measure (Eisinga et al., 2013) indicated high internal consistency $(\rho=.82)$. Psychometric research shows that this measure of extraversion shows strong correlations with established measures, exhibits strong test-retest reliability, and has a similar pattern of correlations with external criteria to other measures of extraversion (Gosling et al., 2003).

Control variables: Remaining personality traits. To control for the possibility that our results may be confounded by other personality characteristics relevant to leadership, we included measures of conscientiousness, emotional stability, and openness to experience, all of which have been shown to predict leader emergence (Judge et al., 2002). Although agreeableness does not predict leadership emergence in meta-analytic research, it does predict leadership effectiveness (Judge et al., 2002), so we included it here to rule out the possibility that leadership network changes are due to this variable. Agreeableness $(\rho=.39)$ was measured with the items "critical, quarrelsome" (reverse-scored) and "sympathetic, warm." Conscientiousness $(\rho=.59)$ was measured with the items "disorganized, careless" (reversescored) and “dependable, self-disciplined." Emotional stability $(\rho=.63)$ was captured with 
the items "anxious, easily upset" (reverse-scored) and "calm, emotionally stable." Openness to experience $(\rho=.47)$ was measured with the items "conventional, uncreative" (reversescored) and "open to new experiences, complex." Participants responded to each item on a seven-point Likert scale and all items were drawn from the TIPI (Gosling et al., 2003). Although the internal consistency estimates for these two-item control variables were lower than typically observed in longer measures, the Big Five traits are broad domains, and lower inter-item correlations for a two-item measure are often considered desirable to ensure adequate content coverage of the item domain.

Control variables: Demographics. Prior research shows that important verbal behaviors, such as length of communication, can shape leadership perceptions (e.g., Anderson \& Kilduff, 2009; Mullen et al., 1989). Individuals who speak in their native language may have an advantage in social settings where they do not have to speak in their second or third language, so we measured whether each person spoke English as their native language and included this binary variable $(1=$ native language speaker, $0=$ non-native language speaker) in our analyses. We coded marital status as a binary variable $(1=$ single, 0 $=$ not single). To control for potential leadership bias against minorities, we included binary control variables reflecting whether someone was a minority $(1=$ yes, $0=$ no $)$ and whether someone was a United States citizen $(1=$ yes, $0=$ no). Finally, to account for the possibility that females may be evaluated differently in leadership contexts than males (e.g., Badura et al., 2018; Eagly \& Karau, 1991), we included gender as a binary variable ( $1=$ female, $0=$ male).

Control variable: Student leadership position. As described above, some individuals succeeded in being elected to a student leadership position within their section. These elected positions could be regarded as a proxy for formal hierarchy within sections, so 
we included a dummy variable reflecting whether the individual was elected to a student leadership position $(1=$ yes, $0=$ no $)$.

Control variable: Initial network size. To ensure that our results are not explained by the possibility that extraverted individuals have larger networks at Time 1, we also included the number of people in the network each person had at Time 1 in each of our models (termed initial network size). We refer to this variable as initial network size, but note that network research sometimes refers to it as indegree centrality (Wasserman \& Faust, 1994).

\section{Analytic Procedure}

In line with prior research that examined individual-level network change with count variables (e.g., Sasovova et al., 2010), we adopted an analytic approach that was suited to count data. Ordinary least squares are inappropriate for count outcomes because they do not account for the highly skewed nature of the dependent variable and the over-dispersion present in the data (i.e., the variance exceeding the mean). Thus, we estimated generalized linear models with a negative binomial log link (Cameron \& Trivedi, 1998; Hilbe, 2014). We estimated robust standard errors to reduce biases due to non-independent observations.

In exploratory network evolution analyses presented below, we supplement our negative binomial models at the ego network level (where we model the number of ties added, maintained, and lost) with Stochastic Actor-Oriented Models (SAOMs; Snijders, 1996; Snijders et al., 2010; Snijders, 2017) to predict the likelihood that a specific tie between ego and alter will change. That is, the negative binomial models test the number of changes that each person experiences across the study period, and the SAOMs test the likelihood that one specific tie will change. SAOMs were estimated using the RSiena package (Ripley et al., 2021, version 1.3.0) in $\mathrm{R}$ ( $\mathrm{R}$ Core Team, 2021, version 4.1.0, and 4.1.0). These exploratory analyses provide further insight into the network evolution processes by modeling the 
network interdependencies inherent in our data and estimating the likelihood that extraversion relates to change in a specific tie between ego and alter. We refer to these models as network evolution models in the text below and provide a brief summary here, although we refer interested readers to more detailed discussions of these models in prior work (for an introduction, see Snijders et al., 2010; Snijders, 2017; Kalish, 2019).

SAOMs are designed to capture the unobserved change processes between two (or more) time points as a continuous Markov process. SAOMs take the observed network (where $x_{i j}=1$ if $i$ sees $j$ as a leader, $x_{i j}=0$ otherwise) as the dependent variable. The core assumption of the SAOM is that the leadership network does not change at once between the two network measurements, but that the observed changes (ties added, maintained, and lost among individuals in the leadership network) occur one after another in a series of small changes called mini steps. Each mini step consists of the actor (ego) deciding whether to add, keep, or lose a tie to another individual in the network. The series of mini steps that links the two measurement points is unobserved and needs to be simulated by the model. ${ }^{1}$ SAOMs take into account endogenous processes inherent to network evolution ${ }^{2}$, such as popularity effects (i.e., the tendency for individuals with larger networks to attract more ties over time), as well as offering insight into how actor attributes, such as extraversion, relate to the likelihood that a specific tie will change over time.

\footnotetext{
${ }^{1}$ For this simulation (and thus estimation) the SAOM splits the dynamic change process into two functions. The rate function captures which actor is given the next opportunity to make a change in the network and the objective function models the multi-nominal choice process that each actor (participant) faces when chosen by the rate function. The chosen actor can nominate another individual as a leader that they do not yet see as a leader, they can decide to drop a nomination to another individual that they previously saw as a leader but now no longer do, or they can keep their network as it is. The model estimates network effects that would account for the observed data and produces parameter estimates for actor attributes, such as extraversion, that may help explain tie choices.

${ }^{2}$ The models exhibited strong fit for statistics relevant for the model (e.g., the number of leadership nominations, the relationship between incoming leadership nominations and extraversion, the relationship between leadership nominations that dissolved and extraversion, and so forth), but fit less well for other statistics, such as patterns of sending leadership nominations among actors in triads, that are observed in our network.
} 


\section{Study 1: Results and Discussion}

We present the means, standard deviations, and correlations for our study variables in Table 1. Individuals each had approximately 70 peers who could view them as leaders at each time point. As shown in Table 1, individuals tended to be more selective of who they considered a leader over time, such that individuals had an average of 3.62 people in their leadership networks at Time 1 and 2.92 people in their leadership networks at Time 2 . To illustrate the specific changes occurring across individuals' leadership networks over time, they attracted an average of 2.21 new people, lost an average of 2.92 people, and maintained an average of .70 people.

Insert Tables 1 and 2 about here

First, we examined whether extraversion was related to emergent leadership in the network at both time points. In other words, did extraverted individuals emerge as informal leaders within the network on each measurement occasion? The answer is yes: Extraversion was positively related to the number of people who perceived the individual as an informal leader at Time $1(b=.55,95 \%$ CI $[.44, .65], p<.001)$ and Time $2(b=.42,95 \%$ CI $[.32, .53]$, $p<.001)$.

\section{New People Entering the Leadership Network}

Recall that our perspective suggests that although extraverted individuals may emerge as leaders, they may experience significant changes to their networks over time. In negative binomial regression analyses predicting the number of people entering the network over time, we found that extraversion exhibited a positive link with the number of new followers added $(b=.29,[95 \% \mathrm{CI}=.18, .41], p<.001)$. These results are shown in Table 2. For example, our model predicts that an extraverted individual (one standard deviation above the mean), 
relative to an introverted individual (one standard deviation below the mean), would attract an additional 1.66 new people over the four-month interval, holding other variables constant. This effect of extraversion on the number of new people in a person's leadership network was observed above and beyond differences in initial leadership network size.

\section{Current People Remaining in the Leadership Network}

Next, we evaluated the likelihood that extraversion is related to the number of people who remained in the leadership network over time. As shown in Table 2, extraversion was positively related to the number of people who remained in the leadership network over time $(b=.30,[95 \% \mathrm{CI}=.18, .43], p<.001)$, above and beyond the statistically significant effect of how many people there were at Time $1(b=.14,[95 \% \mathrm{CI}=.11,17], p<.001)$. To understand the meaning of this leadership network persistence effect, we estimated marginal means: This translates into an additional 1.44 people that were retained across the four-month period when comparing extraverted individuals (one $S D$ above the mean) relative to introverted individuals (one $S D$ below the mean), holding other variables, such as differences in initial network size, constant.

\section{People Leaving the Leadership Network}

We found that extraversion was positively related to the number of people lost $(b=$ $.21,[95 \% \mathrm{CI}=.14, .28], p<.001)$, controlling for the number of people a leader had at Time $1(b=.13,[95 \% \mathrm{CI}=.10,16], p<.001)$. This finding indicates that an extraverted individual (one $S D$ above the mean), relative to an introverted individual (one $S D$ below the mean), would be expected to lose an additional 4.03 people over the four-month interval, even when we account for the number of followers present at Time 1.

\section{Exploratory Analyses}

Curvilinear effects. The hypothesis tests above assume monotonic relationships between extraversion and leadership network change outcomes, but a natural extension of 
these predictions concerns the possibility that extraversion has an impact on network change outcomes up until a point, after which the effect declines. To test the possibility of a curvilinear relationship between extraversion and network change, we added quadratic terms for extraversion to each of the models tested in Table 2. However, we found no statistically significant curvilinear relationship between extraversion and the number of people added $(b=$ $-.02, p=.45)$, number of people maintained $(b=-.03, p=.57)$, or number of people lost $(b=$ $-.03, p=.11)$.

Network evolution analyses. The results of our exploratory SAOM are presented in Table 3. The model takes into account structural effects in the network as well as testing how extraversion relates to tie change. We included four effects to study how extraversion relates to specific tie changes while controlling for endogenous network processes. The sender effect (shown as extraversion ego in Table 3) captures whether individuals with higher extraversion were more likely to nominate others as leaders and is not statistically significant (estimate = $.00, p=.98$ ). The similarity effect (shown as extraversion similarity) models a preference for an individual to send and maintain ties with individuals with similar levels of extraversion and is statistically significant (estimate $=.27, p=.028$ ). The third and fourth effects are of most theoretical interest to us and most closely resemble the relationships studied in our hypothesis tests using negative binomial models above. These effects show a positive creation effect (shown as extraversion-creation) of extraversion on receiving a new leadership tie (estimate $=.24, p<.001)$, meaning that as extraversion increases, the likelihood of being nominated by another individual as a leader in the network also increases. However, we also observed a negative maintenance effect (shown as extraversionmaintenance) in which ties that already exist were more likely to dissolve if the individual who received the leadership nomination was higher in extraversion (estimate $=-.17, p=$ $.031)$. 
Insert Table 3 about here

\section{Discussion}

The results of Study 1 provide initial support for the links between extraversion and the number of new people added, maintained, and lost, above and beyond the effects of initial leadership network size. These findings are particularly noteworthy for establishing these effects in a setting where peers are randomly assigned to each section (i.e., people are approximately equivalent in terms of demographics and industry background) and networks are largely unaffected by a hierarchical structure like those found in formal organizations. Exploratory analyses revealed no significant curvilinear relationships between extraversion and the three network change outcomes. Further, our network evolution models control for endogenous network processes and provide further insight into how extraversion relates to single tie changes over the study period: Individuals with higher extraversion are more likely to receive a new leadership tie over time, but are also more likely to lose a tie that they already had.

These data are, however, also limited in at least two ways. First, although this setting features several advantages, it is also limited in terms of the extent to which these findings may apply to real-world organizations where the enactment of leadership behaviors and changes to emergent leadership networks may be of greater professional consequence. Second, although we controlled for whether the individual was elected to a formal position among the other students in their section, these elected positions may not mirror the effects of a formal hierarchy within an actual organization where there are rank-based differences and formal reporting relationships. This setting also did not allow us to test whether there are differences in network churn among people who are within and outside the formal span of 
control. We therefore conducted a second leadership network change study at a professional services firm to establish these effects in a setting of high external validity.

\section{Study 2: Method}

\section{Participants}

To study leadership network change in a setting with high ecological validity, we collaborated with a large professional services firm in Latin America that specialized in providing wealth management and accountancy services to clients. Due to the knowledgeintensive nature of the work, employees regularly interacted with each other across functions, making the organization an ideal setting for a study of informal leadership change. A human resources manager emailed the first survey invitation to all 1,014 employees at Time 1 and received responses from 919 people for a valid response rate of $90.63 \%$. This first survey contained measures of personality and the informal leadership network. Approximately five months later (similar to the four-month time interval in Study 1), the human resources department emailed a second survey to all 1,017 employees in the company and received responses from 858 people for a valid response rate at Time 2 of $84.36 \%$. This second survey contained measures of the informal leadership network. Demographic (e.g., age, gender) and organizational (e.g., rank, tenure, name of supervisor) variables were collected from the organization. In the time between measurement occasions, 118 people left the company and there were 121 new hires, which were excluded from our analyses so that changes in leadership networks could not be attributed to hiring or turnover, as in similar network change research (e.g., Sasovova et al., 2010, p. 649). The final dataset contained matched surveys from 764 individuals $\left(M_{\mathrm{age}}=36.83, S D_{\mathrm{age}}=8.77,30.1 \%\right.$ women $)$. Please note that due to the sensitive nature of these data, they cannot be made publicly available. Syntax for our models below can be found here:

https://osf.io/34kzs/?view_only=ca31e773c7f042a7992eb5ef8db45af8. 


\section{Data and Measures}

Leadership networks. As in Study 1, we aimed to capture whom each individual perceived to be a leader at Time 1 and Time 2. In both surveys, we presented each participant with the following instructions:

We would like you to think about who you perceive to be a leader at [company name]. Leaders are people who influence others to achieve a common goal. It is important to recognize that people you perceive as a leader may or may not have formal leadership positions in the organization.

In keeping with Study 1, we used the roster approach (Borgatti et al., 2013; Wasserman \& Faust, 1994) and presented each participant with a list of organizational members in alphabetical order, sorted by team. Each participant could choose up to 10 people. As in Study 1, we chose to limit the number of people that could be nominated as a leader to reduce issues with respondent fatigue.

The decision rule for coding leadership ties was the same as in Study 1 and prior network research (e.g., Sasovova et al., 2010): For individual $i$, a leadership tie exists between persons $i$ and $j$ only if person $j$ claimed person $i$ as a leader.

Dependent variables: Leadership network churn. As in Study 1, our outcome variables of interest concerned counts of the number of people entering, remaining in, and leaving each person's informal leadership network. People added was a count of the leadership ties that did not exist at Time 1 that existed at Time 2. People maintained was a count of the leadership ties that existed at Time 1 that also existed at Time 2. People lost was a count of the leadership ties that existed at Time 1 that did not exist at Time 2 . Thus, each participant experienced three possible changes, reflected in counts of the number of people who entered, remained in, and left their network from Time 1 to Time 2. 
Predictor variable: Extraversion. We captured extraversion at Time 1 with the 12item extraversion measure from the Big Five Inventory-2 (BFI-2; Soto \& John, 2017). We asked participants to indicate the extent to which each statement applied to them on a fivepoint scale $(1=$ strongly disagree, $5=$ strongly agree $)$. Example items were "I am someone who is outgoing, sociable," and "I am someone who has an assertive personality." The items exhibited high internal consistency $(\alpha=.81)$.

Control variable: Formal network size. We controlled for the number of individuals who had a formal reporting relationship with each individual (i.e., the person's formal leadership network size). Individuals may experience leadership network changes due to variability in the number of employees reporting directly to them. Thus, for each individual, we included formal network size at Time 1 and formal network size at Time 2, both of which were measured by counting the number of people who directly reported to each individual. This control variable allows us to remove any influences on individuals' informal leadership networks that could be attributed to differences between individuals in the span of control (i.e., formal leadership network size). Importantly, this variable does not reflect whether the direct report considers an individual to be a leader, but whether the individual officially reports to the person as their leader. In exploratory analyses presented below, we also analyzed how network change occurs both within and outside a person's formal span of control.

Control variable: Informal network size. As in Study 1, we included the number of people who considered an individual to be a leader at Time 1 in each of our models to rule out that any changes could be attributed to differences in network size. To distinguish it from the number of people who officially report to the person as their leader, we termed it informal network size. 


\section{Personality control variables: Other Big Five traits, narcissism, and self-}

monitoring. We controlled for several additional personality traits (measured at Time 1) that could serve as potential alternative explanations for our findings. First, as in Study 1, we controlled for conscientiousness $(\alpha=.79)$, neuroticism $(\alpha=.81)$, openness to experience $(\alpha=$ $.74)$, and agreeableness $(\alpha=.68)$ using longer 12 -item measures for each personality variable from the BFI-2 (Soto \& John, 2017). Each item was preceded by the stem "I am someone who..." and was rated on a five-point Likert scale $(1=$ strongly disagree, $5=$ strongly agree $)$. Example items include "is dependable, steady" (conscientiousness), "is relaxed, handles stress well" (emotional stability), "is inventive, finds clever ways to do things" (openness to experience), and "has a forgiving nature" (agreeableness).

We also controlled for narcissism as a potential alternative explanation. Prior research shows that narcissists are more likely to win favorable evaluations upon first meeting others (Back et al., 2010; Brunell et al., 2008) yet are also more likely to lose support over time (Ong et al., 2014). Although meta-analytic research shows that narcissism is not a significant predictor of leader emergence once extraversion is considered (Grijalva et al., 2015), this evidence is based on static evaluations of leadership emergence, whereas our research concerns leadership network change. Therefore, we measured narcissism with the 40-item Narcissistic Personality Inventory (Raskin \& Terry, 1988; $\alpha=.79$ ), in which participants indicated whether the first or second statement in a series of 40 paired statements was closest to their feelings. Example items include "(A) I have a natural talent for influencing people, or (B) I am not good at influencing people."

Finally, because self-monitoring has been implicated in prior research as underpinning network dynamics in the workplace (e.g., Sasovova et al., 2010), we measured it with the 18item Self-Monitoring Scale (Gangestad \& Snyder, 1985; Snyder \& Gangestad, 1986; $\alpha=.64$ ) on a five-point Likert scale ( 1 = strongly disagree, 5 = strongly agree $)$. Example items are "I 
find it hard to imitate the behavior of other people," and "I am not always the person I appear to be."

Control variable: Rank. We included hierarchical rank in the organization to account for potential differences in power, status, or responsibility (where $1=$ entry level, $9=$ executive).

Organizational and demographic control variables. To control for possible gender differences in leadership emergence (e.g., Badura et al., 2018; Eagly \& Karau, 1991), we included gender $($ coded $1=$ female, $0=$ male). As a proxy for overall professional experience, we included age (measured in years). To account for differences in leadership capability arising from expertise due to time with the company or in a particular role, we included company tenure and job tenure (both measured in months).

\section{Analytic Procedure}

We again used a negative binomial generalized linear model to test the relationships between extraversion and social network change outcomes. The negative binomial model is appropriate for skewed count data where the variance exceeds the mean (Cameron \& Trivedi, 1998; Hilbe, 2014). To account for the non-independent observations inherent in social network data, we used robust standard errors. In exploratory analyses presented below, we also include our results of SAOMs that model endogenous network properties (e.g., the tendency for well-connected individuals to attract more ties over time) and test the extent to which extraversion relates to the propensity to form or lose a specific tie over time.

\section{Study 2: Results and Discussion}

The means, standard deviations, and correlations among study variables are presented in Table 4. The overall number of ties at Time 1 was 4,024 (density =1\%), which slightly increased to 4,339 at Time $2($ density $=1 \%)$. At the same time, the informal leadership networks changed: The total number of people added over time was 2,580, maintained was 
2,265 , and lost was 1,759 . On average, individuals had 5.27 people in their leadership networks at Time 1 and 5.68 people at Time 2, and added 3.38 new people, maintained 2.30 people, and lost 2.96 people over time.

Insert Table 4 about here

We examined whether extraversion relates to emergent leadership in the network at Time 1 and Time 2. Results again supported this link between extraversion and emergent leadership in the network: Extraversion was positively related to the number of people who claimed a focal person as an informal leader at Time $1(b=.47,95 \% \mathrm{CI}[.28, .66], p<.001)$ and Time $2(b=.36,95 \%$ CI $[.17, .56], p<.001)$.

\section{New People Entering the Leadership Network}

Our main perspective concerned the network changes that occur over time, despite extraverted individuals having larger leadership networks. As shown in Table 5, we found that extraversion predicted the number of people added to the network over time, $b=.27$, $95 \%$ CI $[.12, .41], p<.001$, controlling for the number of people that formally reported to each person at Time 1 and Time 2, informal leadership network size, as well as other alternative explanations such as rank, tenure, self-monitoring, and narcissism. Using the models shown in Table 5, estimated marginal means from our negative binomial regression model predict that an extraverted individual (one $S D$ above the mean) would add 1.86 people over time, whereas a relatively introverted individual (one $S D$ below the mean) would add 1.22 people over time (holding other variables constant).

Insert Table 5 about here 


\section{Current People Remaining in the Leadership Network}

As shown in Table 5, the higher the extraversion score, the higher the number of people at Time 1 that still considered the person a leader at Time 2, $b=.33,95 \%$ CI [.12, $.54], p=.002$. The predicted number of people maintained for extraverted individuals (one $S D$ above the mean) was .75 , whereas relatively introverted individual (one $S D$ below the mean) would retain only .45 people.

\section{People Leaving the Leadership Network}

We found that extraversion was positively related to the number of followers lost from Time 1 to Time 2, $b=.34,95 \%$ CI $[.20, .48], p<.001$ (Table 5). Importantly, this effect could not be attributed to the number of people in the leadership network that a person had at Time 1. Estimated marginal means from our negative binomial regression model suggest that an extraverted individual would lose 1.92 people, whereas a relatively introverted individual would lose 1.13 people.

\section{Exploratory Analyses}

Curvilinear effects. As in Study 1, we also explored whether extraversion has an influence on leadership network changes up until a point, after which the effect declines (a curvilinear relationship). We added quadratic terms to each of our models shown in Table 5. We found that extraversion did not have a statistically significant curvilinear relationship with the number of people added $(b=-.04, p=.53)$ or the number of people maintained $(b=-$ $.09, p=.32$ ). While we observed a statistically significant curvilinear relationship between extraversion and the number of people lost $(b=-.12,95 \%$ CI $[-.22,-.01], p=.028)$, this effect was not robust to outlier sensitivity analyses.

Network churn within and outside the formal span of control. Formal leadership roles require individuals to behave in ways that are consistent with their role vis-à-vis others. As such, these formal leadership roles may act as strong situations (Meyer et al., 2010; 
Mischel, 1977) that constrain the effects of personality on network churn by minimizing differences in leaderlike behavior that individuals display towards others within their formal of span of control. In contrast, interactions that occur outside of the formal span of control may act as weaker situations where the effects of extraversion on network churn are most pronounced. To test this idea, we created new network churn variables that reflect whether the number of people lost, kept, or added were within or outside the formal span of control, and then used these variables as outcomes. The results are shown in Table 6. Among individuals who are within the span of control (i.e., there is a direct reporting relationship), the more extraverted individuals are, the more likely they are to add new people to their leadership networks over time $(b=.50,95 \%$ CI $[.09, .92], p=.017)$, but were not more likely to maintain a larger number of people $(b=.19,95 \%$ CI $[-.21, .59], p=.348)$, nor were they more likely to lose a larger number of people $(b=-.56,95 \%$ CI $[-1.45, .32], p=.210)$. For network churn outside of the span of control, results show that the more extraverted individuals are, the more likely they are to add new people to their leadership networks $(b=$ $.26,95 \%$ CI $[.11, .40], p<.001)$, keep people in their leadership networks $(b=.31,95 \%$ CI $[.09, .52], p=.005)$, but also lose people in their leadership networks over time $(b=.36,95 \%$ CI $[.22, .50], p<.001)$. These results are consistent with the idea that relationships outside the formal span of control may act as weak situations where the effects of extraversion are especially likely to occur.

Insert Table 6 about here

Network evolution analyses. We present the results of the SAOM in Table 7. We included structural effects to model network processes as in Study 1, as well as additional effects to account for important features of our organizational data. For example, because the 
network showed much stronger hierarchical clustering, we included a network effect for regular transitive triplets in this model. The results for extraversion are similar to those of Study 1 . The sender effect capturing the extent to which extraversion relates to sending a leadership tie to another person was not statistically significant (estimate $=.00, p=.85$ ), and we observed a similarity effect where individuals with similar levels of extraversion were more likely to form a leadership tie (estimate $=.36, p=.004$ ). There was again a positive creation effect in which individuals with a higher level of extraversion were more likely to receive a new leadership tie (estimate $=.15, p<.001$ ), but the negative maintenance effect, which reflects whether extraversion relates to the dissolution of a tie that already exists, was in the expected direction but not statistically significant within common thresholds (estimate $=-.09, p=.087)$.

Insert Table 7 about here

\section{Discussion}

In a professional services firm, we fully replicated the relationship between extraversion and churn within leadership networks found in Study 1. That is, extraverted individuals are more likely to experience a larger number of people entering, remaining in, and leaving their networks. These effects were observed above and beyond the significant influence of the formal organizational structure on leadership network change, as well as the number of people that a person had attracted at Time 1 . Thus, these results surfaced in a setting of high ecological validity and generalizability.

In exploratory analyses, we also found that there were no significant curvilinear effects of extraversion, except for the number of people leaving the network, which did not remain significant in tests where a small number of outliers were not included in the analyses. 
Exploratory analyses of the number of people entering, remaining in, and leaving the leadership network within and outside the span of control revealed an interesting pattern: Although we observed a significant relationship between extraversion and the number of new followers added within the span of control, there were no significant relationships for the number of followers remaining or lost. Yet, in analyses of network churn outcomes among followers outside the span of control, there were significant relationships between extraversion and all outcomes. This finding suggests that holding a formal leadership role may have a protective effect in terms of preventing extraverted individuals from losing followers within their span of control, even as they do so beyond their formal supervisory relationships. Finally, in exploratory tests of how extraversion relates to a single tie changing in network evolution models, we found that extraversion plays a role in the likelihood of receiving a new single tie with another person, but did not find strong empirical evidence in support of the likelihood that a single existing tie would dissolve.

\section{General Discussion}

In this paper, we sought to address a fundamental question: How do extraverted individuals fare as emergent leaders over time? Our network churn perspective captures informal leadership relations between individuals, allowing us to track the number of people entering, remaining in, and leaving each person's network over time. We built on the notion that these leadership relations, like many social relationships, are prone to change over time, and that these changes are linked to extraversion. That is, we proposed that extraverted individuals may endure as emergent leaders (i.e., people who have a large number of others who claim them as informal leaders) but leave a significant number of people who once considered them a leader, but now no longer do, in their wake.

Findings from two studies found support for this network churn perspective. In Study 1, extraverted individuals experienced a larger number of people entering and remaining in 
their leadership networks over time, but also a larger number of people leaving their networks over time. These effects were observed even after controlling for the initial size of a person's leadership networks. In Study 2, we replicated the finding that extraverted individuals experience a larger number of new people entering and remaining in their networks over time, yet also lose a larger number of people. Notably, our results remained statistically significant even after accounting for differences in rank, initial leadership network size, the number of formal followers reporting to a leader, and personality differences in narcissism, self-monitoring, and the other Big Five variables. Exploratory analyses revealed that the occupancy of a formal leadership role may protect extraverted individuals from the significant tendency to lose a greater number of followers within their span of control over time, but does not protect them from losing a greater number of followers outside their span of control. Our stochastic actor-oriented models took into account structural effects within the network while testing the extent to which extraversion relates to the likelihood of receiving a tie from another person over time (supported in both studies), as well as losing an existing tie over time (supported in Study 1).

\section{Theoretical Implications}

The current research offers several important implications for the literatures on extraversion, social networks, and emergent leadership. Because extraversion is so often implicated in studies of interpersonal relations (e.g., Mund et al., 2018), it is critical to understand how this important trait affects one of the most widely studied outcomes (i.e., leadership relations) with the passage of time. The current research offers a point of clarity to this well-established relationship (Emery et al., 2013; Judge et al., 2002), suggesting that the notion of extraverted people as stable, emergent leaders does not quite capture the full story. As our two studies show, extraversion is related to having larger leadership networks (i.e., being an emergent leader) at both time points, but the people in these leadership networks 
change as well. Thus, extraversion is related to leading different people over time. As such, the current research contributes to the growing body of evidence suggesting that extraversion, a trait that has typically been associated with everyday "bright side" behaviors that are often seen as beneficial in social settings (Judge et al., 2009), is more complicated than previously thought.

These findings speak to a likely challenge that extraverted individuals may face in social environments where there is a limit on the number of potential interaction partners (and therefore people who could potentially view them as a leader). Our findings suggest that extraverted individuals must attract new ties from individuals who previously did not consider them a leader if they are to maintain their status as emergent leaders with the passage of time. If so, then extraversion should be related to waning network size in social environments (e.g., small teams or committees) where extraverted individuals are unable to attract new ties from other individuals. Similarly, the link between extraversion and the number of people leaving the leadership network also suggests that researchers need to collect ratings from all possible individuals in the social environment who may perceive a focal person as a leader, especially those who are outside of the individual's formal span of control. Repeated sampling of a fixed set of individuals within the individual's formal span of control using traditional (i.e., rating scales) psychometric approaches to capturing leadership emergence are likely to miss the full spectrum of network changes we observed here.

These network changes are most pronounced in social environments where there is no strict formal hierarchy (as in the student sample in Study 1) or social interactions between people are occurring outside the formal span of control (there is no formal reporting relationship between the two individuals). Within the formal span of control, extraversion was positively related to the number of new people added, but unrelated to the number of people lost or kept within the span of control. These exploratory results suggest that in weak 
situations (Meyer et al., 2010; Mischel, 1977) where social interactions take place outside of the formal span of control, extraverted individuals are especially likely to exhibit network churn by losing a larger number of people, adding a larger number of people, and keeping a larger number of people.

We also highlight the need for a shift in conversation from the apparent stability of emergent leaders to the variability of the people that see them as leaders. That is, given the amount of network churn - the addition of new entrants and the exit of old followers in the leadership network - observed in our data, it is important for researchers to consider the potential for people to abandon support for informal leaders, as well as the potential for people to become interested in new leaders. For instance, losing a larger number of people over time may present challenges for informal leaders in the workplace. Suggesting opportunities for change, enlisting the support of individuals in the organization, and executing one's ideas are all activities that draw upon a person's ability to lead others (e.g., see Anderson et al., 2008b). Losing followers over time may diminish informal leaders' capacity to draw social support for their initiatives (Zee \& Bolger, 2019), especially in settings such as small team meetings where lost followers may be present. For example, in ad hoc committees or project-based teams where lost followers are present, extraverted individuals may experience difficulty exercising informal leadership because people who dropped them as leaders may gossip and spread negative information among a set of people who also interact with the would-be leader (Feinberg et al., 2012). A focus on leadership network churn therefore offers a richer, nuanced view of the challenges facing informal leaders working in dynamic environments.

\section{Limitations and Future Directions}

Our findings must be interpreted in light of limitations that offer new opportunities for future research. First, the number of leaders that each person could nominate (outgoing ties) 
was limited. We chose this approach to limit response fatigue. Although our results are based on changes to the number of incoming ties, rather than the number of outgoing ties, this methodological limitation means that the absence of leadership nominations for some individuals could indicate that others did not fail to see them as leaderlike, but rather that others did not see them as sufficiently leaderlike to be nominated in the number of spaces allowed. In one sense, these leadership networks could be regarded as conservative measures of leadership ties because individuals nominated the people who they perceived as most leaderlike. However, from these data alone, it remains unclear whether the effects we observed would be attenuated (or strengthened) if participants were able to nominate an unlimited number of people as leaders. The consistency of results across our two studies and the fact that leadership tends to be concentrated in a limited number of individuals helps add confidence to our conclusions.

Second, we sought to answer the call for scholars to explore leadership relations over time (Liden et al., 2016, p. 143), as well as increased attention to network perspectives (Carter et al., 2015; Denis et al., 2012, p. 211). Network change studies are uncommon in the literature, in large part owing to the great difficulty in collecting data over time (Liden et al., 2016). We note those same difficulties in our data collection efforts, which also limited our ability to collect measurement points beyond two. However, to strengthen confidence in the nature of these effects, additional measurement points (e.g., a third or fourth time point) would offer further insight. That is, our data do not allow us to infer what would happen to leadership networks beyond the two occasions observed here, but we would expect the same effects to continue to occur over longer time horizons. We call on future research to investigate the conditions in which these effects may be strengthened or attenuated over time. For example, our effects may be attenuated in more competitive organizational contexts, particularly if contests are zero-sum, where dominant leaders are preferred (Davidai \& Ongis, 
2019). Similarly, our effects may be moderated by the extent to which the business environment is uncertain, in line with prior research showing that greater uncertainty engenders a preference for more dominant leaders (Kakkar \& Sivanathan, 2017). Investigating changes to leadership networks over extended time horizons is a promising frontier for network research.

Third, our results add new insight into the ongoing discussion of how people choose leaders over time. Implicit leadership theory (Lord \& Maher, 1991) suggests that individuals are likely to be perceived as leaders to the extent that they match pre-existing prototypes or ideas that observers have concerning prototypical leaders. In this vein, Kalish and Luria (2021) noted that time may play an important role in how this implicit leadership evaluation process unfolds, such that in the early period of network formation, readily observable characteristics such as extraversion may be important, but become less important over time as people begin to know each other and rely increasingly on less readily observable characteristics, such as conscientiousness. Our data suggest that extraversion does not become a non-significant predictor of leadership network size across time. In both studies, extraversion predicted leader emergence (i.e., indegree centrality; the overall number of leadership nominations a person receives) at both time points. Thus, at the ego network level, our data suggests that extraversion relates to network centrality and churn, leading some individuals to leave, others to stay, and new people to enter the network. This finding suggests that research can benefit from analyzing data in terms of the overall number of leadership nominations a person receives and these three facets of network change, allowing for a richer understanding of how the people in the network surrounding a person may evolve, even if the person's centrality remains relatively high.

Finally, we encourage scholars to continue exploring the consequences of losing followers. Existing research points to the negative consequences of losing status over time, 
even if the person attains an eventual position of high status (Pettit et al., 2013). Losing support from key individuals could undermine an extraverted person's ability to influence at work. If such effects occur over a long period, the long trail of former followers could make it difficult for extraverted individuals to lead others within the informal network at work. For example, research in behavioral economics suggests that loss of followers may lead to reputational damage (Yoeli et al., 2013). Others in the network may spread this information throughout its members, who may make negative inferences about the character of the extraverted person who lost so many followers (Feinberg et al., 2014). As one such consequence, extraverted people who lose many followers may be viewed as less trustworthy and, as a result, other members in the network may behave less prosocially toward them (Haley \& Fessler, 2005), thus constraining their organizational advancement (Ng et al., 2005). We encourage future research to conduct longitudinal analyses examining the consequences of losing followers, which would be helpful in understanding the outcomes of these leader-follower changes.

\section{Conclusion}

Throughout the literatures on personality, social networks, and emergent leadership, there is little question as to the value of extraversion for understanding why some individuals emerge as informal leaders among others. But as the current research suggests, the dominant view of extraverted individuals among an unchanging cast of people seems incomplete. Rather, our network churn perspective suggests a shift in the conversation from the stability of extraverted leaders to the variability of their networks. Extraverted individuals are dynamic, informal leaders who indeed emerge and persist as such—but not necessarily among the same set of people. 


\section{References}

Ames, D. R., \& Flynn, F. J. (2007). What breaks a leader: The curvilinear relation between assertiveness and leadership. Journal of Personality and Social Psychology, 92, 307324. https://doi.org/10.1037/0022-3514.92.2.307

Ames, D. R., Lee, A., \& Wazlawek, A. (2017). Interpersonal assertiveness: Inside the balancing act. Social and Personality Psychology Compass, 11(6), Article e12317. https://doi.org/10.1111/spc3.12317

Anderson, C., Ames, D. R., \& Gosling, S. D. (2008a). Punishing hubris: The perils of overestimating one's status in a group. Personality and Social Psychology Bulletin, 34(1), 90-101. https://doi.org/10.1177/0146167207307489

Anderson, C., John, O. P., Keltner, D., \& Kring, A. M. (2001). Who attains social status? Effects of personality and physical attractiveness in social groups. Journal of Personality and Social Psychology, 81(1), 116-132. https://doi.org/10.1037/00223514.81 .1 .116

Anderson, C., \& Kilduff, G. J. (2009). Why do dominant personalities attain influence in face-to-face groups? The competence-signaling effects of trait dominance. Journal of Personality and Social Psychology, 96, 491-503. https://doi.org/10.1037/a0014201

Anderson, C., Spataro, S. E., \& Flynn, F. J. (2008b). Personality and organizational culture as determinants of influence. Journal of Applied Psychology, 93, 702-710. https://doi.org/10.1037/0021-9010.93.3.702

Asendorpf, J. B., \& Wilpers, S. (1998). Personality effects on social relationships. Journal of Personality and Social Psychology, 74(6), 1531-1544. https://doi.org/10.1037/00223514.74.6.1531 
Ashton, M. C., Lee, K., \& Paunonen, S. V. (2002). What is the central feature of extraversion? Social attention versus reward sensitivity. Journal of Personality and Social Psychology, 83(1), 245-252. https://doi.org/10.1037/0022-3514.83.1.245

Back, M. D., Schmukle, S. C., \& Egloff, B. (2010). Why are narcissists so charming at first sight? Decoding the narcissism-popularity link at zero acquaintance. Journal of Personality and Social Psychology, 98(1), 132-145. https://doi.org/10.1037/a0016338

Badura, K. L., Grijalva, E., Newman, D. A., Yan, T. T., \& Jeon, G. (2018). Gender and leadership emergence: A meta-analysis and explanatory model. Personnel Psychology, 71(3), 335-367. https://doi.org/10.1111/peps.12266

Barrick, M. R., Stewart, G. L., \& Piotrowski, M. (2002). Personality and job performance: Test of the mediating effects of motivation among sales representatives. Journal of Applied Psychology, 87(1), 43-51. https://doi.org/10.1037/0021-9010.87.1.43

Bendersky, C., \& Shah, N. P. (2013). The downfall of extraverts and rise of neurotics: The dynamic process of status allocation in task groups. Academy of Management Journal, 56(2), 387-406. http://dx.doi.org/10.5465/amj.2011.0316

Bolger, N., \& Eckenrode, J. (1991). Social relationships, personality, and anxiety during a major stressful event. Journal of Personality and Social Psychology, 61, 440449. https://doi.org/10.1037/0022-3514.61.3.440

Bolger, N., Foster, M., Vinokur, A. D., \& Ng, R. (1996). Close relationships and adjustments to a life crisis: The case of breast cancer. Journal of Personality and Social Psychology, 70(2), 283-294. https://doi.org/10.1037/0022-3514.70.2.283

Borgatti, S. P., Everett, M. G., \& Johnson, J. C. (2013). Analyzing social networks. Sage Publications Limited.

Brass, D. J., \& Krackhardt, D. (1999). The social capital of twenty-first-century leaders. In J. G. (J.) Hunt, G. E. Dodge, \& L. Wong (Eds.), Monographs in leadership and 
management, Vol. 1. Out-of-the-box leadership: Transforming the twenty-first-century army and other top-performing organizations (pp. 179-194). Elsevier Science/JAI Press.

Brunell, A. B., Gentry, W. A., Campbell, W. K., Hoffman, B. J., Kuhnert, K. W., \& DeMarree, K. G. (2008). Leader emergence: The case of the narcissistic leader. Personality and Social Psychology Bulletin, 34, 16631676. https://doi.org/10.1177/0146167208324101

Burkhardt, M. E., \& Brass, D. J. (1990). Changing patterns or patterns of change: The effects of a change in technology on social network structure and power. Administrative Science Quarterly, 35, 104-127. https://doi.org/10.2307/2393552

Cain, S. (2012). Quiet: The power of introverts in a world that can't stop talking. Crown Publishing Group.

Cameron, A. C., \& Trivedi, P. K. (1998). Regression analysis of count data. Cambridge University Press.

Carter, D. R., DeChurch, L. A., Braun, M. T., \& Contractor, N. S. (2015). Social network approaches to leadership: An integrative conceptual review. Journal of Applied Psychology, 100, 597-622. https://doi.org/10.1037/a0038922

Chen, J., Qiu, L., \& Ho, M-H. R. (2020). A meta-analysis of linguistic markers of extraversion: Positive emotion and social process words. Journal of Research in Personality, 89, article 104035. https://doi.org/10.1016/j.jrp.2020.104035

Coggan, P. (2020, November 17). Firms will need to find new ways to bring employees together. The Economist. https://www.economist.com/the-worldahead/2020/11/17/firms-will-need-to-find-new-ways-to-bring-employees-together 
Crant, J. M., Kim, T.-Y., \& Wang, J. (2011). Dispositional antecedents of demonstration and usefulness of voice behavior. Journal of Business and Psychology, 26, 285-297. https://doi.org/10.1007/s10869-010-9197-y

Davidai, S., \& Ongis, M. (2019). The politics of zero-sum thinking: The relationship between political ideology and the belief that life is a zero-sum game. Science Advances, 5(12), eaay3761. https://doi.org/10.1126/sciadv.aay3761

Denis, J.-L., Langley, A., \& Sergi, V. (2012). Leadership in the plural. Academy of Management Annals, 6(1), 211-283. https://doi.org/10.5465/19416520.2012.667612

DeRue, D. S., \& Ashford, S. J. (2010). Who will lead and who will follow? A social process of leadership identity construction in organizations. Academy of Management Review, 35, 627-647. https://doi.org/10.5465/amr.35.4.zok627

Eagly, A. H., \& Karau, S. J. (1991). Gender and the emergence of leaders: A metaanalysis. Journal of Personality and Social Psychology, 60, 685710. https://doi.org/10.1037/0022-3514.60.5.685

Eaton, L. G., \& Funder, D. C. (2003). The creation and consequences of the social world: An interactional analysis of extraversion. European Journal of Personality, 17(5), 375395. https://doi.org/10.1002/per.477

Eisinga, R., Te Grotenhuis, M., \& Pelzer, B. (2013). The reliability of a two-item scale: Pearson, Cronbach, or Spearman-Brown? International Journal of Public Health, 58, 637-642. https://doi.org/10.1007/s00038-012-0416-3

Emery, C., Calvard, T. S., \& Pierce, M. E. (2013). Leadership as an emergent group process: A social network study of personality and leadership. Group Processes \& Intergroup Relations, 16(1), 28-45. https://doi.org/10.1177/1368430212461835

Ensari, N., Riggio, R. E., Christian, J., \& Carslaw, G. (2011). Who emerges as a leader? Meta-analyses of individual differences as predictors of leadership emergence. 
Personality and Individual Differences, 51, 532-536.

https://doi.org/10.1016/j.paid.2011.05.017

Fang, R., Landis, B., Zhang, Z., Anderson, M. H., Shaw, J. D., \& Kilduff, M. (2015).

Integrating personality and social networks: A meta-analysis of personality, network position, and work outcomes in organizations. Organization Science, 26, 1243-1260. https://doi.org/10.1287/orsc.2015.0972

Feiler, D. C., \& Kleinbaum, A. M. (2015). Popularity, similarity, and the network extraversion bias. Psychological Science, 26(5), 593-603.

ttps://doi.org/10.1177/0956797615569580

Feinberg, M., Willer, R., \& Schultz, M. (2014). Gossip and ostracism promote cooperation in groups. Psychological Science, 25, 656-664.

https://doi.org/10.1177/0956797613510184

Feinberg, M., Willer, R., Stellar, J., \& Keltner, D. (2012). The virtues of gossip: Reputational information sharing as prosocial behavior. Journal of Personality and Social Psychology, 102(5), 1015-1030. https://doi.org/10.1037/a0026650

Feingold, A. (1983). Correlates of public speaking attitude. The Journal of Social Psychology, 120(2), 285-286. https://doi.org/10.1080/00224545.1983.9713225

Fleeson, W., Malanos, A. B., \& Achille, N. M. (2002). An intraindividual process approach to the relationship between extraversion and positive affect: Is acting extraverted as "good" as being extraverted? Journal of Personality and Social Psychology, 83, 14091422. https://doi.org/10.1037/0022-3514.83.6.1409

Freeman, L. C. (1979). Centrality in social networks conceptual clarification. Social Networks, 1(3), 215-239. https://doi.org/10.1016/0378-8733(78)90021-7 
Gangestad, S., \& Snyder, M. (1985). "To carve nature at its joints": On the existence of discrete classes in personality. Psychological Review, 92, 317-349. https://doi.org/10.1037/0033-295X.92.3.317

Gosling, S. D., Ko, S. J., Mannarelli, T., \& Morris, M. E. (2002). A room with a cue: Personality judgments based on offices and bedrooms. Journal of Personality and Social Psychology, 82, 379-398. https://doi.org/10.1037/0022-3514.82.3.379

Gosling, S. D., Rentfrow, P. J., \& Swann Jr., W. B. (2003). A very brief measure of the BigFive personality domains. Journal of Research in Personality, 37, 504-528. https://doi.org/10.1016/S0092-6566(03)00046-1

Grant, A. M., \& Gino, F. (2010). A little thanks goes a long way: Explaining why gratitude expressions motivate prosocial behavior. Journal of Personality and Social Psychology, 98, 946-955. https://doi.org/10.1037/a0017935

Grant, A. M., Gino, F., \& Hofmann, D. A. (2011). Reversing the extraverted leadership advantage: The role of employee proactivity. Academy of Management Journal, 54, 528-550. https://doi.org/10.5465/amj.2011.61968043

Grant, A. M., Parker, S., \& Collins, C. (2009). Getting credit for proactive behavior: Supervisor reactions depend on what you value and how you feel. Personnel Psychology, 62, 31-55. https://doi.org/10.1111/j.1744-6570.2008.01128.x

Grijalva, E., Harms, P. D., Newman, D. A., Gaddis, B. H., \& Fraley, R. C. (2015). Narcissism and leadership: A meta-analytic review of linear and nonlinear relationships. Personnel Psychology, 68, 1-47. https://doi.org/10.1111/peps.12072

Haley, K. J., \& Fessler, D. M. T. (2005). Nobody's watching?: Subtle cues affect generosity in an anonymous economic game. Evolution and Human Behavior, 26, 245-256. https://doi.org/10.1016/j.evolhumbehav.2005.01.002 
Hanna, A. A., Smith, T. A., Kirkman, B. L., \& Griffin, R. W. (2021). The emergence of emergent leadership: A comprehensive framework and directions for future research. Journal of Management, 47(1), 76-104. https://doi.org/10.1177/0149206320965683

Hasan, S., \& Bagde, S. (2015). Peers and network growth: Evidence from a natural experiment. Management Science, 61, 2536-2547. https://doi.org/10.1287/mnsc.2014.2109

Hilbe, J. (2014). Modeling count data. Cambridge University Press.

Hogan, R., Curphy, G. J., \& Hogan, J. (1994). What we know about leadership: Effectiveness and personality. American Psychologist, 49, 493-504. https://doi.org/10.1037/0003066X.49.6.493

Hogan, R., \& Kaiser, R. B. (2005). What we know about leadership. Review of General Psychology, 9, 169-180. https://doi.org/10.1037/1089-2680.9.2.169

Hu, J., Zhang, Z., Jiang, K., \& Chen, W. (2019). Getting ahead, getting along, and getting prosocial: Examining extraversion facets, peer reactions, and leadership emergence. Journal of Applied Psychology, 104(11), 1369-1386. https://doi.org/10.1037/ap10000413

Judge, T. A., Bono, J. E., Ilies, R., \& Gerhardt, M. W. (2002). Personality and leadership: A qualitative and quantitative review. Journal of Applied Psychology, 87, 765-780. https://doi.org/10.1037/0021-9010.87.4.765

Judge, T. A., Piccolo, R. F., \& Kosalka, T. (2009). The bright and dark sides of leader traits: A review and theoretical extension of the leader trait paradigm. The Leadership Quarterly, 20, 855-875. https://doi.org/10.1016/j.leaqua.2009.09.004

Kahnweiler, J. B. (2018). The introverted leader: Building on your quiet strength (2nd ed.). Berrett-Koehler Publishers. 
Kakkar, H., \& Sivanathan, N. (2017). When the appeal of a dominant leader is greater than a prestige leader. Proceedings of the National Academy of Sciences, 114, 6734-6739. https://doi.org/10.1073/pnas.1617711114

Kalish, Y., \& Luria, G. (2021). Traits and time in leadership emergence: A longitudinal study. The Leadership Quarterly, 32(2), 101443. https://doi.org/10.1016/j.leaqua.2020.101443

Kilduff, M., \& Krackhardt, D. (1994). Bringing the individual back in: A structural analysis of the internal market for reputation in organizations. Academy of Management Journal, 37(1), 87-108. https://doi.org/10.5465/256771

Kleinbaum, A. M. (2018). Reorganization and tie decay choices. Management Science, 64, 2219-2237. https://doi.org/10.1287/mnsc.2016.2705

Knoke, D., \& Burt, R. S. (1983). Prominence. In R. S. Burt \& M. J. Minor (Eds.), Applied network analysis (pp. 195-222). SAGE Publications.

Krackhardt, D., \& Hanson, J. R. (1993, July-August). Informal networks: The company behind the chart. Harvard Business Review. https://hbr.org/1993/07/informal-networksthe-company-behind-the-chart

Kuijpers, E., Pickett, J., Wille, B., \& Hofmans, J. (2021). Do you feel better when you behave more extraverted than you are? The relationship between cumulative counterdispositional extraversion and positive feelings. Personality and Social Psychology Bulletin. https://doi.org/10.1177\%2F01461672211015062

LePine, J. A., \& Van Dyne, L. (2001). Voice and cooperative behavior as contrasting forms of contextual performance: Evidence of differential relationships with Big Five personality characteristics and cognitive ability. Journal of Applied Psychology, 86, 326-336. https://doi.org/10.1037/0021-9010.86.2.326 
Liden, R. C., Anand, S., \& Vidyarthi, P. (2016). Dyadic relationships. Annual Review of Organizational Psychology and Organizational Behavior, 3, 139-166. https://doi.org/10.1146/annurev-orgpsych-041015-062452

Lord, R. G., de Vader, C. L., \& Alliger, G. M. (1986). A meta-analysis of the relation between personality traits and leadership perceptions: An application of validity generalization procedures. Journal of Applied Psychology, 71, 402-410. https://doi.org/10.1037/0021-9010.71.3.402

Lufkin, B. (2021, March 2). Why it's wrong to look at work-life balance as an achievement. BBC Workplace. https://www.bbc.com/worklife/article/20210302-why-work-lifebalance-is-not-an-achievement

MacLaren, N. G., Yammarino, F. J., Dionne, S. D., Sayama, H., Mumford, M. D., Connelly, S., Martin, R. W., Mulhearn, T. J., Todd, E. M., Kulkarni, A., Cao, Y., \& Ruark, G. A. (2020). Testing the babble hypothesis: Speaking time predicts leader emergence in small groups. The Leadership Quarterly, 31(5), article 101409. https://doi.org/10.1016/j.leaqua.2020.101409

Mann, R. D. (1959). A review of the relationships between personality and performance in small groups. Psychological Bulletin, 56, 241-270. https://doi.org/10.1037/h0044587

McCrae, R. R., \& John, O. P. (1992). An introduction to the five-factor model and its applications. Journal of Personality, 60, 175-215. https://doi.org/10.1111/j.14676494.1992.tb00970.x

McNiel, J. M., \& Fleeson, W. (2006). The causal effects of extraversion on positive affect and neuroticism on negative affect: Manipulating state extraversion and state neuroticism in an experimental approach. Journal of Research in Personality, 40, 529550. https://doi.org/10.1016/j.jrp.2005.05.003 
McNiel, J. M., Lowman, J. C., \& Fleeson, W. (2010). The effect of state extraversion on four types of affect. European Journal of Personality, 24, 18-35. https://doi.org/10.1002/per.738

Mehl, M. R., Gosling, S. D., \& Pennebaker, J. W. (2006). Personality in its natural habitat: Manifestations and implicit folk theories of personality in daily life. Journal of Personality and Social Psychology, 90, 862-877. https://doi.org/10.1037/00223514.90.5.862

Merton, R. K. (1968). The Matthew effect in science: The reward and communication systems of science are considered. Science, 159(3810), 56-63.

Meyer, R. D., Dalal, R. S., \& Hermida, R. (2010). A review and synthesis of situational strength in the organizational sciences. Journal of Management, 36, 121-140.

Mischel, W. (1977). The interaction of person and situation. In D. Magnusson \& N. S. Endler (Eds.), Personality at the crossroads: Current issues in interactional psychology: 333-352. Lawrence Erlbaum.

Mouw, T. (2006). Estimating the causal effect of social capital: A review of recent research. Annual Review of Sociology, 32, 79-102. https://doi.org/10.1146/annurev.soc.32.061604.123150

Mullen, B., Salas, E., \& Driskell, J. E. (1989). Salience, motivation, and artifact as contributions to the relation between participation rate and leadership. Journal of Experimental Social Psychology, 25, 545-559. https://doi.org/10.1016/00221031(89)90005-X

Mund, M., Jeronimus, B. F., \& Neyer, F. J. (2018). Personality and social relationships: As thick as thieves. In C. Johansen (Ed.), Personality and Disease: Scientific proof vs. wishful thinking (pp. 153-183). Academic Press. https://doi.org/10.1016/B978-0-12805300-3.00009-8 
Ng, T. W. H., Eby, L. T., Sorensen, K. L., \& Feldman, D. C. (2005). Predictors of objective and subjective career success: A meta-analysis. Personnel Psychology, 58, 367-408. https://doi.org/10.1111/j.1744-6570.2005.00515.x

Ong, C. W., Roberts, R., Arthur, C. A., Woodman, T., \& Akehurst, S. (2014). The leader ship is sinking: A temporal investigation of narcissistic leadership. Journal of Personality, 84, 237-247. https://doi.org/10.1111/jopy.12155

Opt, S. K., \& Loffredo, D. A. (2000). Rethinking communication apprehension: A MyersBriggs perspective. The Journal of Psychology, 134, 556-570. https://doi.org/10.1080/00223980009598236

Percy, S. (2019, June 10). Do extroverts make better leaders? Forbes. https://www.forbes.com/sites/sallypercy/2019/06/10/do-extroverts-make-better-leaders/

Pettit, N. C., Sivanathan, N., Gladstone, E., \& Marr, J. C. (2013). Rising stars and sinking ships: Consequences of status momentum. Psychological Science, 24, 1579-1584. https://doi.org/10.1177/0956797612473120

Pollet, T. V., Roberts, S. G. B., \& Dunbar, R. I. M. (2011). Extraverts have larger social network layers, but do not feel emotionally closer to individuals at any layer. Journal of Individual Differences, 32(3), 161-169. https://doi.org/10.1027/1614-0001/a000048

R Core Team (2021). R: A language and environment for statistical computing. R Foundation for Statistical Computing, Vienna, Austria. URL https://www.R-project.org/.

Raskin, R., \& Terry, H. (1988). A principal-components analysis of the Narcissistic Personality Inventory and further evidence of its construct validity. Journal of Personality and Social Psychology, 54, 890-902. https://doi.org/10.1037/00223514.54.5.890 
Ripley, R., Snijders, T., Boda, Z., Vörös, A., \& Preciado, P. (2019). Manual for Siena version 4.0. Technical report, Oxford: University of Oxford, Department of Statistics; Nuffield College.

Sasovova, Z., Mehra, A., Borgatti, S. P., \& Schippers, M. C. (2010). Network churn: The effects of self-monitoring personality on brokerage dynamics. Administrative Science Quarterly, 55, 639-670. https://doi.org/10.2189/asqu.2010.55.4.639

Scherer, K. R. (1978). Personality inference from voice quality: The loud voice of extroversion. European Journal of Social Psychology, 8, 467-487. https://doi.org/10.1002/ejsp.2420080405

Selden, M., \& Goodie, A. S. (2018). Review of the effects of Five Factor Model personality traits on network structures and perceptions of structure. Social Networks, 52, 81-99. https://doi.org/10.1016/j.socnet.2017.05.007

Smillie, L. D. (2013). Extraversion and reward processing. Current Directions in Psychological Science, 22, 167-172. https://doi.org/10.1177/0963721412470133

Smillie, L. D., Cooper, A. J., Wilt, J., \& Revelle, W. (2012). Do extraverts get more bang for the buck? Refining the affective-reactivity hypothesis of extraversion. Journal of Personality and Social Psychology, 103, 306-326. https://doi.org/10.1037/a0028372

Smillie, L. D., Wilt, J., Kabbani, R., Garratt, C., \& Revelle, W. (2015). Quality of social experience explains the relation between extraversion and positive affect. Emotion, 15, 339-349. https://doi.org/10.1037/emo0000047

Snijders, T. (1996). Stochastic actor-oriented models for network change. Journal of Mathematical Sociology, 21: 149-172.

Snijders, T. (2017). Stochastic actor-oriented models for network dynamics. Annual Reviews of Statistics and Its Application, 4: 343-362. 
Snijders, T. (2021, 2. November). Response to: Difference in transitivity across groups. RSiena user group. https://tinyurl.com/bdd6mwpx

Snijders, T., Pattison, P., Robins, G., and Handcock, M. (2006). New specifications for exponential random graph models. Sociological Methodology, 36: 99-153.

Snijders, T., Van de Bunt, G., \& Steglich, C. (2010). Introduction to stochastic actor-based models for network dynamics. Social Networks, 32(1): 44-60.

Snook, S., Nohria, N., \& Khurana, R. (Eds.). (2012). The handbook for teaching leadership: Knowing, doing, and being. Sage.

Snyder, M., \& Gangestad, S. (1986). On the nature of self-monitoring: Matters of assessment, matters of validity. Journal of Personality and Social Psychology, 51, 125-139. https://doi.org/10.1037/0022-3514.51.1.125

Soto, C. J., \& John, O. P. (2017). The next Big Five Inventory (BFI-2): Developing and assessing a hierarchical model with 15 facets to enhance bandwidth, fidelity, and predictive power. Journal of Personality and Social Psychology, 113, 117-143. https://doi.org/10.1037/pspp0000096

Spark, A., \& O’Connor, P. J. (2020). State extraversion and emergent leadership: Do introverts emerge as leaders when they act like extraverts? The Leadership Quarterly, 32(3), 101474. https://doi.org/10.1016/j.leaqua.2020.101474

Stadtfeld, C., \& Block, P. (2017). Interactions, actors, and time: Dynamic network actor models for relational events. Sociological Science, 4: 318-352.

Swann Jr., W. B., \& Rentfrow, P. J. (2001). Blirtatiousness: Cognitive, behavioral, and physiological consequences of rapid responding. Journal of Personality and Social Psychology, 81, 1160-1175. https://doi.org/10.1037/0022-3514.81.6.1160

van Zalk, M. H. W., Nestler, S., Geukes, K., Hutteman, R., \& Back, M. D. (2020). The codevelopment of extraversion and friendships: Bonding and behavioral interaction 
mechanisms in friendship networks. Journal of Personality and Social Psychology, 118(6), 1269-1290. https://doi.org/10.1037/pspp0000253

Vater, A., \& Schröder-Abé, M. (2015). Explaining the link between personality and relationship satisfaction: Emotion regulation and interpersonal behaviour in conflict discussions. European Journal of Personality, 29, 201-215. https://doi.org/10.1002/per.1993

Vinchur, A. J., Schippmann, J. S., Switzer III, F. S., \& Roth, P. L. (1998). A meta-analytic review of predictors of job performance for salespeople. Journal of Applied Psychology, 83, 586-597. https://doi.org/10.1037/0021-9010.83.4.586

Wasserman, S., \& Faust, K. (1994). Social network analysis: Methods and applications. Cambridge University Press.

Watson, D., \& Clark, L. A. (1997). Extraversion and its positive emotional core. In R. Hogan, J. Johnson, \& S. Briggs (Eds.), Handbook of personality psychology (pp. 767-793). Academic Press. https://doi.org/10.1016/b978-012134645-4/50030-5

Wilson, R. E., Harris, K., \& Vazire, S. (2015). Personality and friendship satisfaction in daily life: Do everyday social interactions account for individual differences in friendship satisfaction? European Journal of Personality, 29, 173-186. https://doi.org/10.1002/per.1996

Yoeli, E., Hoffman, M., Rand, D. G., \& Nowak, M. A. (2013). Powering up with indirect reciprocity in a large-scale field experiment. Proceedings of The National Academy of Sciences, 110(Supplement 2), 10424-10429. https://doi.org/10.1073/pnas.1301210110

Zee, K. S., \& Bolger, N. (2019). Visible and invisible social support: How, why, and when. Current Directions in Psychological Science, 28, 314-320. https://doi.org/10.1177/0963721419835214 
Zelenski, J. M., Whelan, D. C., Nealis, L. J., Besner, C. M., Santoro, M. S., \& Wynn, J. E. (2013). Personality and affective forecasting: Trait introverts underpredict the hedonic benefits of acting extraverted. Journal of Personality and Social Psychology, 104, 1092-1108. https://doi.org/10.1037/a0032281 
Table 1

Means, Standard Deviations, and Correlations (Study 1)

\begin{tabular}{|c|c|c|c|c|c|c|c|c|c|c|c|c|c|c|c|c|c|c|}
\hline Variables & $M$ & $S D$ & 1 & 2 & 3 & 4 & 5 & 6 & 7 & 8 & 9 & 10 & 11 & 12 & 13 & 14 & 15 & 16 \\
\hline 1. Age & 27.98 & 2.48 & & & & & & & & & & & & & & & & \\
\hline 2. Gender & .39 & .49 & -.16 & & & & & & & & & & & & & & & \\
\hline 3. US citizen & .60 & .49 & -.13 & .06 & & & & & & & & & & & & & & \\
\hline 4. Minority & .51 & .50 & .08 & .10 & -.39 & & & & & & & & & & & & & \\
\hline 5. Single & .47 & .50 & -.07 & -.06 & -.07 & .03 & & & & & & & & & & & & \\
\hline 6. Native speaker & .36 & .48 & -.10 & .02 & .43 & -.28 & -.07 & & & & & & & & & & & \\
\hline 7. Extraversion & 4.64 & 1.60 & -.02 & .06 & .01 & -.05 & .03 & .01 & & & & & & & & & & \\
\hline 8. Agreeableness & 5.01 & 1.19 & -.06 & .22 & .09 & .08 & -.06 & .05 & .09 & & & & & & & & & \\
\hline 9. Conscientiousness & 5.64 & 1.11 & -.02 & .14 & -.03 & -.08 & .01 & .11 & .04 & .16 & & & & & & & & \\
\hline 10. Emotional stability & 5.02 & 1.29 & .02 & -.19 & .02 & -.02 & -.06 & .02 & .04 & .15 & .17 & & & & & & & \\
\hline 11. Openness & 5.21 & 1.15 & .06 & .07 & -.07 & -.01 & .09 & -.03 & .28 & .17 & .11 & .15 & & & & & & \\
\hline 12. Student leader & 0.08 & 0.26 & .01 & -.02 & .02 & -.04 & -.03 & .09 & .14 & .04 & .10 & .00 & .01 & & & & & \\
\hline 13. Number of followers (T1) & 3.62 & 7.86 & .04 & -.02 & .12 & -.09 & -.01 & .14 & .30 & .07 & .01 & .01 & .10 & .19 & & & & \\
\hline 14. Number of followers (T2) & 2.92 & 6.25 & .06 & -.06 & .15 & -.18 & .00 & .17 & .25 & .02 & .05 & .04 & .07 & .08 & .50 & & & \\
\hline 15. Number of followers added & 2.21 & 4.80 & .04 & -.04 & .15 & -.18 & -.02 & .14 & .22 & .00 & .05 & .04 & .06 & .04 & .25 & .93 & & \\
\hline 16. Number of followers maintained & .70 & 2.51 & .08 & -.07 & .08 & -.11 & .03 & .17 & .21 & .05 & .03 & .02 & .07 & .12 & .78 & .71 & .42 & \\
\hline 17. Number of followers lost & 2.92 & 6.08 & .01 & .00 & .11 & -.07 & -.02 & .12 & .30 & .07 & .00 & .00 & .10 & .20 & .97 & .35 & .15 & .59 \\
\hline
\end{tabular}

Note. $N=545$ (MBA students). Gender is coded 1 for female, 0 for male. Correlations with an absolute value greater than .08 and .11 are significant at $p<.05$ and $p<.01$, respectively. Point-biserial correlations are used for correlations between dummy variables and continuous variables. 
Table 2

Negative Binomial Regression Analyses Predicting Leadership Network Change (Study 1)

\begin{tabular}{|c|c|c|c|c|c|c|}
\hline \multirow[b]{2}{*}{ Predictor } & \multicolumn{2}{|c|}{$\begin{array}{c}\text { Number of } \\
\text { Followers Added }\end{array}$} & \multicolumn{2}{|c|}{$\begin{array}{l}\text { Number of } \\
\text { Followers } \\
\text { Maintained }\end{array}$} & \multicolumn{2}{|c|}{$\begin{array}{l}\text { Number of } \\
\text { Followers Lost }\end{array}$} \\
\hline & $b$ & $S E$ & $b$ & $S E$ & $b$ & $S E$ \\
\hline Intercept & -.19 & 1.13 & -5.00 & 1.48 & -1.31 & .74 \\
\hline \multicolumn{7}{|l|}{ Control } \\
\hline Age & -.03 & .03 & .06 & .04 & -.01 & .02 \\
\hline Gender & -.24 & .20 & -.37 & .22 & .07 & .10 \\
\hline US citizen & $.53 * *$ & .19 & .12 & .26 & .13 & .12 \\
\hline Single & -.12 & .17 & .09 & .19 & -.14 & .09 \\
\hline Native speaker & .14 & .20 & .31 & .23 & .09 & .11 \\
\hline Minority & $-.47 * *$ & .19 & -.33 & .24 & -.06 & .10 \\
\hline Network size (T1) & $.05^{* * *}$ & .01 & $.14 * * *$ & .02 & $.13 * * *$ & .01 \\
\hline Student leader & -.23 & .31 & .03 & .33 & .03 & .19 \\
\hline Agreeableness & -.08 & .07 & -.02 & .09 & -.05 & .04 \\
\hline Conscientiousness & .01 & .08 & .08 & .11 & -.06 & .04 \\
\hline Emotional stability & .05 & .07 & -.11 & .09 & .06 & .04 \\
\hline Openness to experience & .01 & .08 & .01 & .10 & .03 & .05 \\
\hline Extraversion & $.29 * * *$ & .06 & $.30 * * *$ & .06 & $.21 * * *$ & .04 \\
\hline Log pseudolikelihood & \multicolumn{2}{|c|}{-938.54} & \multicolumn{2}{|c|}{-347.37} & \multicolumn{2}{|c|}{-864.25} \\
\hline$N$ & \multicolumn{2}{|c|}{545} & \multicolumn{2}{|c|}{545} & \multicolumn{2}{|c|}{545} \\
\hline Pseudo $R^{2}$ & \multicolumn{2}{|c|}{.05} & \multicolumn{2}{|c|}{.26} & \multicolumn{2}{|c|}{.22} \\
\hline
\end{tabular}

Note. Robust standard errors are estimated. Gender is coded as 1 for female and 0 for male. Dummy variables are included in these models for sections (not shown for stylistic purposes). $* p<.05, * * p<.01, * * * p<.001$ (two-tailed) 


\section{Table 3}

Stochastic Actor-Oriented Modeling Results Predicting Tie-Level Changes (Study 1)

\begin{tabular}{|c|c|c|}
\hline Effects & Estimate & $S E$ \\
\hline \multicolumn{3}{|l|}{ Network Effects } \\
\hline Outdegree (density) & $-2.37 * * *$ & .34 \\
\hline Reciprocity & $.65 * * *$ & .14 \\
\hline GWESP I -> K -> J & $1.68 * * *$ & .31 \\
\hline Indegree_-popularity (sqrt) & .09 & .07 \\
\hline Indegree—activity (sqrt) & $-.14 * * *$ & .04 \\
\hline Outdegree-activity (sqrt) & -.07 & .08 \\
\hline \multicolumn{3}{|l|}{ Attribute Effects } \\
\hline Gender alter & -.06 & .06 \\
\hline Gender ego & -.04 & .04 \\
\hline Same gender & .15 & .04 \\
\hline Minority alter & $-.18 * *$ & .06 \\
\hline Minority ego & $-.10 *$ & .04 \\
\hline Same minority & .02 & .04 \\
\hline US citizen alter & .12 & .07 \\
\hline US citizen ego & -.04 & .05 \\
\hline Both US citizen & $.11 * *$ & .04 \\
\hline Student leader alter & -.03 & .12 \\
\hline Student leader ego & .18 & .10 \\
\hline Both student leader & .14 & .11 \\
\hline Single alter & -.05 & .05 \\
\hline Openness alter & .01 & .03 \\
\hline Conscientiousness alter & .05 & .03 \\
\hline Agreeableness alter & -.02 & .02 \\
\hline Emotional stability alter & .01 & .02 \\
\hline Extraversion alter - maintenance & $-.17 *$ & .08 \\
\hline Extraversion alter-creation & $.24 * * *$ & .05 \\
\hline Extraversion ego & .00 & .02 \\
\hline Extraversion similarity & $.27 *$ & .12 \\
\hline
\end{tabular}

Note. The rate functions ranged between 13.796 and $22.873(\mathrm{~m}=17.574)$, meaning that the model gave each student on average 17.6 change opportunities to change their network. Outdegree (density) is the intercept of the multinomial choice models and models the number of ties in the network. Reciprocity refers to the propensity for a tie between ego and alter to be reciprocated. GWESP = Geometrically Weighted Edgewise Shared Partners (Snijders et al, 2006) refers to the tendency to close transitive leadership paths (e.g., when A sees B as a leader, and $\mathrm{B}$ sees $\mathrm{C}$ as a leader, $\mathrm{A}$ is more likely to also see $\mathrm{C}$ as a leader). It models transitive closure of leadership ties, but each bridging leader only adds half as much to the 
log-odds of tie formation as the previous one did. Indegree-popularity (sqrt) refers to propensity of those with many incoming leadership nominations to receive even more; we added the square root to the structural effect to account for the possibility that adding ties beyond a certain point will have a diminished effect on the propensity for a tie to a wellconnected actor to occur. Indegree-activity (sqrt) refers to the tendency to send fewer leadership nominations the more leadership nominations an actor receives; it was not assumed that the effect of incoming leadership nominations linearly changed the propensity to send leadership nominations. Outdegree-activity (sqrt) refers to the tendency for those who send many leadership nominations to send even more. We added to the model three types of effects for attributes: sender effects (the propensity for an attribute to change the likelihood of a tie being sent or maintained, denoted as ego), receiver effects (the propensity for an attribute to change the likelihood of a tie being received, denoted as alter), and similarity effects (the propensity for similar levels of an attribute to change the likelihood of a tie existing between ego and alter, denoted as similarity). All attributes are mean-centered. The creation effect captures only the tendency to send a new tie versus not creating a new tie. The maintenance effect captures only the effect of maintaining an existing tie over not maintaining this tie. All other effects model both the creation of new ties, as well as their maintenance over time. Note that dummy variables (not shown) for each section are included in these models but none was significant, meaning the clusters did not differ in their overall tendency to send leadership nominations.

$* p<.05, * * p<.01, * * * p<.001$ (two-tailed) 
Table 4

Means, Standard Deviations, and Correlations (Study 2)

\begin{tabular}{|c|c|c|c|c|c|c|c|c|c|c|c|c|c|c|}
\hline Variable & $M$ & $S D$ & 1 & 2 & 3 & 4 & 5 & 6 & 7 & 8 & 9 & 10 & 11 & 12 \\
\hline 1. Age & 36.83 & 8.77 & & & & & & & & & & & & \\
\hline 2. Gender & .70 & .46 & .13 & & & & & & & & & & & \\
\hline 3. Company tenure & 110.05 & 92.01 & .77 & .18 & & & & & & & & & & \\
\hline 4. Job tenure & 21.87 & 23.77 & .40 & .09 & .44 & & & & & & & & & \\
\hline 5. Rank & 5.60 & 1.64 & .05 & .21 & .14 & .00 & & & & & & & & \\
\hline 6. Formal network size (T1) & .86 & 2.84 & .20 & -.02 & .14 & .10 & -.17 & & & & & & & \\
\hline 7. Formal network size (T2) & .88 & 2.87 & .20 & -.03 & .12 & .10 & -.16 & .90 & & & & & & \\
\hline 8. Informal network size & 5.27 & 17.97 & .16 & -.09 & .09 & .07 & .31 & .41 & .39 & & & & & \\
\hline 9. Narcissism & 18.34 & 5.72 & -.04 & -.10 & -.00 & .03 & .01 & .11 & .09 & .08 & & & & \\
\hline 10. Self-monitoring & 6.96 & 2.87 & -.10 & -.18 & -.08 & -.07 & -.04 & .05 & .04 & .06 & .47 & & & \\
\hline 11. Agreeableness & 5.86 & .58 & .12 & .17 & .11 & .06 & .11 & .01 & .02 & .05 & .08 & -.03 & & \\
\hline 12. Conscientiousness & 6.23 & .61 & .15 & .15 & .11 & .10 & .13 & -.00 & .01 & .03 & .15 & -.08 & .48 & \\
\hline 13. Neuroticism & 2.44 & .75 & -.02 & .10 & -.00 & .01 & .06 & -.09 & -.09 & -.09 & -.25 & -.08 & -.46 & -.36 \\
\hline 14. Openness & 5.45 & .71 & -.06 & -.08 & -.06 & -.06 & -.08 & .03 & .02 & .10 & .31 & .22 & .25 & .20 \\
\hline 15. Extraversion & 5.47 & .78 & .05 & .04 & .05 & .01 & -.02 & .14 & .13 & .17 & .54 & .37 & .37 & .35 \\
\hline 16. No. of followers added & 3.38 & 8.68 & .18 & -.09 & .11 & .04 & -.35 & .48 & .47 & .88 & .07 & .07 & .05 & .02 \\
\hline 17. No. of followers lost & 2.96 & 7.37 & .17 & -.08 & .14 & .09 & -.36 & .42 & .40 & .95 & .10 & .09 & .06 & .01 \\
\hline 18. No. of followers maintained & 2.30 & 11.25 & .14 & -.10 & .05 & .06 & -.26 & .38 & .37 & .98 & .06 & .03 & .05 & .03 \\
\hline
\end{tabular}




\begin{tabular}{lcccccc}
\hline \multicolumn{1}{c}{ Variable } & $M$ & $S D$ & 13 & 14 & 15 & 16 \\
\hline 14. Openness & 5.45 & .71 & -.24 & & & \\
15. Extraversion & 5.47 & .78 & -.41 & .40 & .11 & .18 \\
16. No. of followers added & 3.38 & 8.68 & -.11 & .11 & .20 & .88 \\
17. No. of followers lost & 2.96 & 7.37 & -.10 & .09 & .14 & .83 \\
18. No. of followers maintained & 2.30 & 11.25 & -.08 & .86 \\
\hline
\end{tabular}

Note. $N=764$. Correlations that have an absolute value greater than .07 are significant at $p<.05$. Point-biserial correlations are used for correlations between dummy variables and continuous variables. 
Table 5

Negative Binomial Regression Analyses Predicting Leadership Network Change (Study 2)

\begin{tabular}{|c|c|c|c|c|c|c|}
\hline \multirow[b]{2}{*}{ Predictor } & \multicolumn{2}{|c|}{$\begin{array}{c}\text { Number of } \\
\text { Followers Added }\end{array}$} & \multicolumn{2}{|c|}{$\begin{array}{l}\text { Number of } \\
\text { Followers } \\
\text { Maintained }\end{array}$} & \multicolumn{2}{|c|}{$\begin{array}{c}\text { Number of } \\
\text { Followers Lost }\end{array}$} \\
\hline & $b$ & $S E$ & $b$ & $S E$ & $b$ & $S E$ \\
\hline Intercept & 1.42 & .82 & -.93 & 1.12 & .86 & .67 \\
\hline \multicolumn{7}{|l|}{ Control } \\
\hline Age & -.01 & .01 & -.02 & .01 & $-.02 * *$ & .01 \\
\hline Gender & .03 & .11 & -.15 & .13 & .10 & .09 \\
\hline Company tenure & $.00 * * *$ & .00 & .00 & .00 & $.00 * * *$ & .00 \\
\hline Job tenure & $-.01 * *$ & .00 & .00 & .00 & $-.01 * *$ & .00 \\
\hline Rank & $-.32 * * *$ & .04 & $-.27 * * *$ & .06 & $-.24 * * *$ & .04 \\
\hline Formal network size (T1) & .02 & .03 & $.05^{* *}$ & .02 & .02 & .02 \\
\hline Formal network size (T2) & $.13 * * *$ & .03 & $.12 * * *$ & .02 & $.04 *$ & .02 \\
\hline Informal network size (T1) & $.04 * * *$ & .01 & $.06 * * *$ & .02 & $.05 * * *$ & .01 \\
\hline Narcissism & -.01 & .01 & -.01 & .01 & -.01 & .01 \\
\hline Self-monitoring & $.04 *$ & .02 & .01 & .02 & .02 & .02 \\
\hline Agreeableness & -.03 & .09 & .11 & .13 & -.02 & .09 \\
\hline Conscientiousness & -.05 & .09 & -.08 & .12 & -.12 & .08 \\
\hline Neuroticism & -.15 & .09 & $-.01 * *$ & .10 & -.05 & .06 \\
\hline Openness & -.01 & .06 & .01 & .08 & .00 & .05 \\
\hline Extraversion & $.27 * * *$ & .07 & $.33 * * *$ & .11 & $.34 * * *$ & .07 \\
\hline Log pseudolikelihood & \multicolumn{2}{|c|}{-1335.88} & \multicolumn{2}{|c|}{-882.82} & \multicolumn{2}{|c|}{-1295.96} \\
\hline$N$ & \multicolumn{2}{|c|}{764} & \multicolumn{2}{|c|}{764} & \multicolumn{2}{|c|}{764} \\
\hline Pseudo $R^{2}$ & \multicolumn{2}{|c|}{.17} & \multicolumn{2}{|c|}{.22} & \multicolumn{2}{|c|}{.18} \\
\hline
\end{tabular}

Note. Robust standard errors are estimated. Gender is coded as 1 for female and 0 for male. $* p<.05, * * p<.01, * * * p<.001$ (two-tailed) 
Table 6

Negative Binomial Regression Analyses Predicting Number of Formal and Discretionary Follower Changes (Study 2)

\begin{tabular}{|c|c|c|c|c|c|c|c|c|c|c|c|c|}
\hline \multirow[b]{2}{*}{ Predictor } & \multicolumn{2}{|c|}{$\begin{array}{c}\begin{array}{c}\text { Number of } \\
\text { formal followers } \\
\text { added }\end{array} \\
\end{array}$} & \multicolumn{2}{|c|}{$\begin{array}{l}\text { Number of } \\
\text { formal followers } \\
\text { maintained }\end{array}$} & \multicolumn{2}{|c|}{$\begin{array}{c}\text { Number of } \\
\text { formal followers } \\
\text { lost }\end{array}$} & \multicolumn{2}{|c|}{$\begin{array}{c}\text { Number of } \\
\text { discretionary } \\
\text { followers added }\end{array}$} & \multicolumn{2}{|c|}{$\begin{array}{l}\text { Number of } \\
\text { discretionary } \\
\text { maintained }\end{array}$} & \multicolumn{2}{|c|}{$\begin{array}{l}\text { Number of } \\
\text { discretionary } \\
\text { followers los }\end{array}$} \\
\hline & $b$ & $S E$ & $b$ & $S E$ & $b$ & $S E$ & $b$ & $S E$ & $b$ & $S E$ & $b$ & $S E$ \\
\hline Intercept & 3.73 & 2.22 & -1.14 & 2.34 & -9.75 & 3.62 & 1.58 & .83 & -1.00 & 1.15 & 1.06 & .68 \\
\hline \multicolumn{13}{|l|}{ Control } \\
\hline Age & .03 & .02 & .00 & .02 & .02 & .03 & -.01 & .01 & -.02 & .01 & $-.02 *$ & .01 \\
\hline Gender & -.18 & .32 & .22 & .24 & .30 & .42 & .05 & .11 & -.15 & .13 & .09 & .09 \\
\hline Company & .00 & .00 & .00 & .00 & .00 & .00 & $.00 * *$ & .00 & $.00 *$ & .00 & $.00 * * *$ & .00 \\
\hline Job tenure & $.01 * * *$ & .00 & .00 & .00 & .00 & .01 & $-.01 * *$ & .00 & .00 & .00 & $-.01 * *$ & .00 \\
\hline Rank & $-.25 * * *$ & .07 & $-.54 * * *$ & .09 & $-.31 *$ & .13 & $-.32 * * *$ & .04 & $-.25 * * *$ & .06 & $-.24 * * *$ & .04 \\
\hline No. of formal followers (T1) & .26 & .02 & $.26 * * *$ & .04 & $.29 * * *$ & .03 & .04 & .02 & .00 & .04 & -.02 & .02 \\
\hline No. of formal followers (T2) & $.09 *$ & .05 & $.13^{* *}$ & .04 & .03 & .08 & $.09 * *$ & .03 & $.08 *$ & .04 & $.07 * * *$ & .02 \\
\hline Total no. of followers (T1) & -.01 & .00 & .00 & .01 & .00 & .00 & $.04 * * *$ & .01 & $.07 * * *$ & .02 & $.05 * * *$ & .01 \\
\hline Narcissism & -.01 & .02 & .02 & .03 & .04 & .04 & -.01 & .01 & -.01 & .01 & -.01 & .01 \\
\hline Self-monitoring & -.02 & .04 & .01 & .04 & .01 & .05 & $.04 *$ & .02 & .02 & .02 & .02 & .02 \\
\hline Agreeableness & -.19 & .23 & .04 & .25 & $.84 *$ & .37 & -.03 & .09 & .07 & .13 & -.06 & .09 \\
\hline Conscientiousness & -.02 & .23 & -.01 & .22 & .09 & .32 & -.07 & .09 & -.04 & .12 & -.12 & .08 \\
\hline Emotional stability & -.28 & .27 & -.28 & .31 & .23 & .36 & -.16 & .09 & -.01 & .11 & -.06 & .06 \\
\hline Openness & -.12 & .19 & -.14 & .15 & .34 & .33 & -.01 & .07 & .03 & .09 & .00 & .05 \\
\hline Extraversion & $.50 *$ & .21 & .19 & .20 & -.56 & .45 & $.26 * * *$ & .07 & $.31 *$ & .11 & $.36 * * *$ & .07 \\
\hline Log pseudolikelihood & \multicolumn{2}{|c|}{-175.10} & \multicolumn{2}{|c|}{-242.84} & \multicolumn{2}{|c|}{-111.78} & \multicolumn{2}{|c|}{-1319.83} & \multicolumn{2}{|c|}{-831.52} & \multicolumn{2}{|c|}{-1287.53} \\
\hline$N$ & \multicolumn{2}{|c|}{764} & \multicolumn{2}{|c|}{764} & \multicolumn{2}{|c|}{764} & \multicolumn{2}{|c|}{764} & \multicolumn{2}{|c|}{764} & \multicolumn{2}{|c|}{764} \\
\hline Pseudo $R^{2}$ & \multicolumn{2}{|c|}{.43} & \multicolumn{2}{|c|}{.41} & \multicolumn{2}{|c|}{.42} & \multicolumn{2}{|c|}{.17} & \multicolumn{2}{|c|}{.22} & \multicolumn{2}{|c|}{.18} \\
\hline
\end{tabular}

Note. $N=764$. Unstandardized coefficients and robust standard errors are reported. $* p<.05 * * p<.01 * * * p<.001$ 


\section{Table 7}

Stochastic Actor-Oriented Modeling Results Predicting Tie-Level Changes (Study 2)

\begin{tabular}{|c|c|c|}
\hline Effects & Estimate & $S E$ \\
\hline \multicolumn{3}{|l|}{ Network Effects } \\
\hline Outdegree (density) & $-4.84 * * *$ & .08 \\
\hline Reciprocity & $.29 *$ & .12 \\
\hline Transitive triplets & $.59 * * *$ & .04 \\
\hline Indegree - popularity (centered) & $-.06 * * *$ & .00 \\
\hline Indegree—popularity (sqrt) & $.78 * * *$ & .03 \\
\hline Indegree—activity (sqrt) & $-.08 * * *$ & .02 \\
\hline Outdegree-activity (centered) & $-.02 * * *$ & .01 \\
\hline \multicolumn{3}{|l|}{ Attribute Effects } \\
\hline Rank alter & $-.08 * * *$ & .02 \\
\hline Rank difference & .00 & .01 \\
\hline Same team & $1.38 * * *$ & .06 \\
\hline Age alter & $.01 * * *$ & .00 \\
\hline Age ego & .00 & .00 \\
\hline Age similarity & $.34 * * *$ & .11 \\
\hline Gender alter & $-.09 * *$ & .04 \\
\hline Gender ego & $.08^{*}$ & .04 \\
\hline Same gender & .05 & .03 \\
\hline Company tenure alter & .00 & .00 \\
\hline Company tenure ego & .00 & .00 \\
\hline Company tenure similarity & $.27 * * *$ & .08 \\
\hline Job tenure alter & .00 & .00 \\
\hline Job tenure ego & .00 & .00 \\
\hline Job tenure similarity & .01 & .07 \\
\hline Narcissism alter & $-.01 *$ & .00 \\
\hline Self-monitoring alter & .00 & .01 \\
\hline Agreeableness alter & .03 & .03 \\
\hline Conscientiousness alter & .06 & .03 \\
\hline Neuroticism alter & .00 & .03 \\
\hline Openness alter & -.02 & .02 \\
\hline Extraversion alter-maintenance & -.09 & .05 \\
\hline Extraversion alter-creation & $.15^{* * *}$ & .04 \\
\hline Extraversion ego & .00 & .02 \\
\hline Extraversion similarity & $.36 * *$ & .12 \\
\hline
\end{tabular}

Note. The rate function was between 13.354, meaning that the model gave each member of the network on average 13.4 change opportunities to change their network. Outdegree 
(density) is the intercept of the multinomial choice models and models the number of ties in the network. Reciprocity refers to the propensity for a tie between ego and alter to be reciprocated. Transitivity refers to the tendency for linear ordering (e.g., if A sees B as a leader, $\mathrm{B}$ sees $\mathrm{C}$ as a leader, then $\mathrm{A}$ will see $\mathrm{C}$ as a leader). Indegree-popularity (sqrt) refers to propensity of those with many incoming leadership nominations to receive even more; we added the square root to the structural effect to account for the possibility that adding ties beyond a certain point will have a diminished effect on the propensity for a tie to a wellconnected actor to occur. Indegree-activity (sqrt) refers to the tendency to send fewer leadership nominations the more leadership nominations one receives; again, it was not assumed that the effect of incoming leadership nominations linearly changed the propensity to send leadership nominations. Outdegree-activity (sqrt) refers to the tendency for those who send many leadership nominations to send even more. We added to the model three types of attribute effects: sender effects (the propensity for an attribute to change the likelihood of a tie being sent or maintained, denoted as ego), receiver effects (the propensity for an attribute to change the likelihood of a tie being received, denoted as alter), and similarity effects (the propensity for similar levels of an attribute to change the likelihood of a tie existing between ego and alter, denoted as similarity). All attributes are mean-centered. The creation effect captures only the tendency to send a new tie versus not creating this new tie. The maintenance effect captures only the effect of maintaining an existing tie over not maintaining this tie. All other effects model both the creation of new ties, as well as their maintenance over time.

$* p<.05, * * p<.01, * * * p<.001$ (two-tailed) 


\section{Figure 1}

Social Network Churn: People Entering, Remaining in, and Leaving Leadership Networks over Time

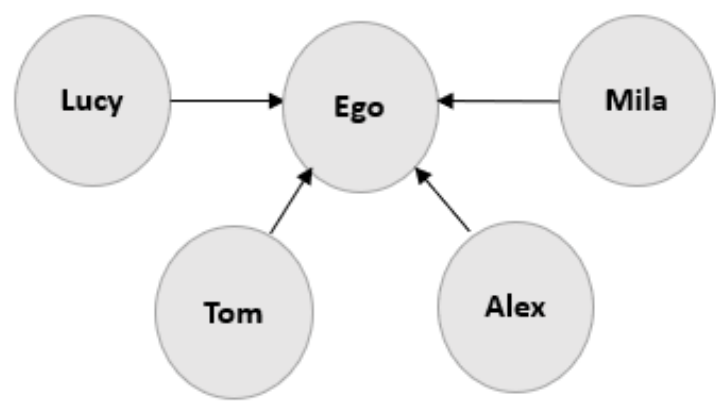

Time 1

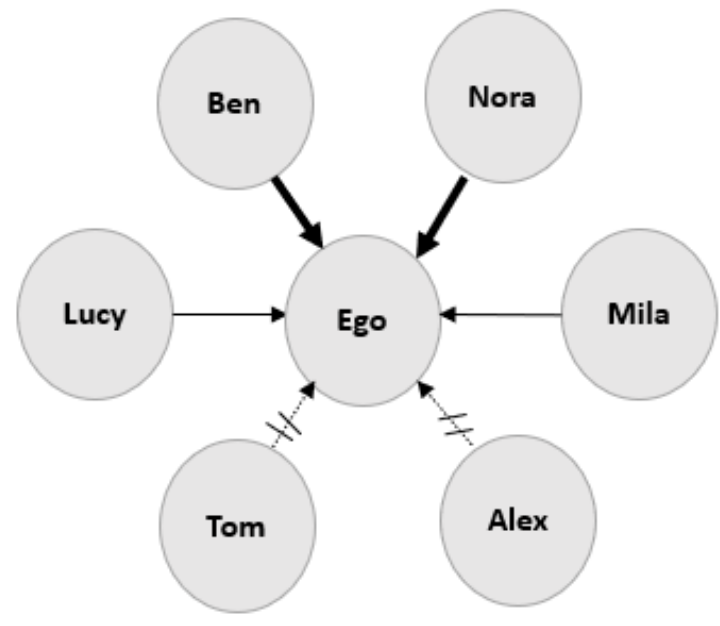

Time 2

Note. The informal leadership network of a hypothetical individual across time. At Time 1, the leader is nominated by four people, denoted by solid black lines. At Time 2, the individual is nominated by four people again, but retained two people, lost two people, and gained two people. Connections between people (alters) are not shown for stylistic purposes. 